\title{
Planning of Food-Energy-Water-Waste (FEW2) nexus for sustainable development
}

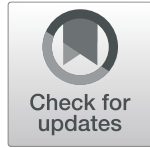

Bowen Feng ${ }^{1}$, Koen H. van Dam², Miao Guo², Nilay Shah², Stephen Passmore ${ }^{3}$ and Xiaonan Wang ${ }^{1^{*}}$ (i)

\begin{abstract}
It is critical for reliable infrastructure planning to address the Food-Energy-Water-Waste (FEW2) nexus at system level. This paper presents the applicability of resilience.io platform across water, energy and waste sectors (including food and agricultural waste) with focus on waste-to-energy pathway, aiming to establish the optimal FEW2 nexus based on economic and environmental indicators. A rich array of technology options, including water production facilities, clean energy technologies and waste-to-energy conversions are evaluated to meet the demand of water and energy (mainly gas and electricity), and the treatment requirement of waste and wastewater. A case study of Hunter Region, the largest region in Australia, is presented in this study, featuring the supply and demand context of developed countries. A full set of scenarios, including business-as-usual (BAU), water and wastewater, power plant decommission, waste-to-energy and policy intervention, is created to present FEW2 nexus from the perspective of individual nodes and the whole system. The results signal the benefits of biogas and syngas generation from anaerobic digestion and gasification for waste-to-energy pathway, alongside findings in water and energy sectors. The outcome of this analysis can then form the foundation of regional planning involving relevant stakeholders, with the modelling tools supporting scenario evaluation and collaborative learning to reach consensus in view of different performance indicators including financial and environmental metrics.
\end{abstract}

Keywords: Integrated planning, Decision support, Hunter region, Agent-based modelling, Resource technology network optimisation

\section{Introduction}

The Food-Energy-Water-Waste (FEW2) Nexus concept characterises the interconnected generation, allocation and consumption processes of the four elements. As shown in Fig. 1, when generating, allocating and consuming one of food, energy and water, it is impossible to avoid generating, allocating and consuming the other two [2]. Unconsumed food mostly turns into food waste, while waste management processes also involve the generation and consumption of both water and energy [3]. The inherently intertwined relationship amongst the four indicates the necessity of utilising the nexus concept as a tool, to address problems encountered when attempting to achieve sustainability for individual elements.

According to the Food and Agriculture Organisation of United Nations in 2011, it is estimated that about 1.3

\footnotetext{
* Correspondence: chewxia@nus.edu.sg

${ }^{1}$ Department of Chemical and Biomolecular Engineering, National University of Singapore, Singapore 117585, Singapore

Full list of author information is available at the end of the article
}

billion tonnes of global food is wasted or lost, which accounts for approximately one third of total food production [4]. Wasting food means wasting water and energy, since producing, processing and consuming of food contribute to about $70 \%$ of global water withdrawn and $30 \%$ global energy consumed [5]. Besides post-consumer food waste, enormous organic waste is also generated from food production processes. About $60 \%$ of a slaughtered animal mass cannot be converted to edible flesh and becomes abattoir waste. In the United State, the annual abattoir waste generation is about 1.4 billion tonnes [6]. Animal's manure is another example of waste generation from food production, amounting to approximately 2 billion ton per year in the United State [7], which is about 300 times to the human faeces generated in American [8]. Approximately $330 \mathrm{~km}^{3}$ per year of municipal wastewater is generated globally, a significant amount of which is food waste from dairy processing and beverage manufacturing [9]. In 2016, the World Bank estimated 2.01 billion tonnes of municipal solid 


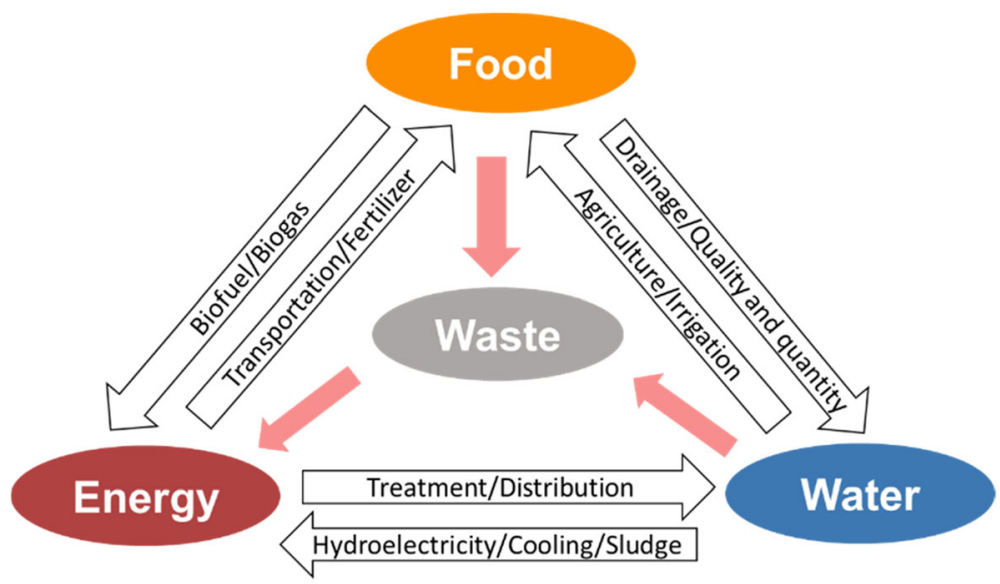

Fig. 1 The intertwined relationship amongst food, energy, water and waste [1]

waste (MSW) is generated in the city, much of which is discarded food waste. With rapid urbanisation and population growth, the number is projected to reach 3.40 billion tonnes per year by the middle of this century [10]. The waste streams are viewed as unwanted hitches by waste generators, but also rich organic feedstocks for waste processors. Within the FEW2 nexus, wastes may be further processed to produce a combination of valuable products and energy resources including heat, electricity and gas [11]. This closely links to the development of circular economy, which is receiving increasing attention globally as a way to balance economic development with environmental and resources protection $[12,13]$. The complete life cycles of biological products (e.g. food) and utilities (e.g. biogas and electricity) need to be identified to account for any environmental and economic impacts in a closed loop, in order to increase the efficiency of resource use, reduce waste generation and carbon emissions, and as a result, achieve a resilient future of cities and regions.

Waste-to-Energy (WtE) technologies is reported by World Energy Council as a viable solution to simultaneously address the challenges of energy supply, waste management and greenhouse gas (GHG) emissions so as to achieve circular economy $[14,15]$. Continuing population growth is expected to increase global energy demand by at least $27 \%$ from 2010 to 2050 [14]. The need to expand the share of clean energy also drives the waste treatment towards WtE pathway. The selection and allocation of WtE facilities are constrained by the interrelated resources within FEW2 nexus, including their spatial distribution, demand profile, connected transportation network, the capacity of facilities and mass and energy balance of technologies. The financial and environmental feasibility of planned facilities should also be evaluated under a continuous time scale to ensure longterm sustainability [16]. A system (or system thinking) approach, as a way of tackling complex issues by thinking of them as an interlinked network of subsystems and elements, would stand a unique position to support decision-making process for infrastructure planning. This is often realised by computational modelling, a prevailing tool to account for the complex interconnection within FEW2 nexus while comprehending the need of being eco-friendly and economically feasible $[17,18]$.

Previously, researchers have conducted system analysis on demand and supply optimisation of subcomponent(s) of the FEW2 nexus. Complete urban water system models have found to be developed in recent years. Rozos and Makropoulos's Urban Water Optioneering Tool (UWOT) is built to simulate the whole water supply system from household demand to reservoir, while tracing wastewater from household generation, through wastewater treatment system, to the water bodies [19]. Behzadian et al.'s WaterMet2 is another comprehensive water and wastewater model, which includes the management of supply-demand balancing, network flow, energy usage and greenhouse gas emissions [20]. A review of prior studies also shows that the topic of energy system modelling is becoming more and more popular. Keirstead et al. reviewed a total of 219 studies and identified a major challenge in these works: the transportation variables between regions are often excluded in system design models [21]. Many studies examined the interaction between two nodes in the FEW2 nexus [2], such as water and energy systems [22] and waste-to-energy systems [23]. Nonetheless, an emerging trend is observed to model the system by connecting all the nodes to exploit potential synergies [24, 25]. Garcia and You identified systems engineering, which applies system thinking in designing and managing complex systems, as an efficient tool for waste management under FEW2 nexus [26]. This is in line with Bieber et al.'s conclusion that a FEW2 system 
approach can improve the benefits across all the underlying sectors [27]. As opposed to system engineering, system modelling approach, which uses models to conceptualise and construct large systems, provides insights on various potential options prior to the implementation of systems engineering [28]. It is thus extremely prevalent to bridge the gap on incorporating FEW2 system modelling into decision-making tools, which should also resolve supply and demand details in a spatial and temporal scale.

Previous works by Triantafyllidis et al., Wang et al. and Bieber et al. have demonstrated the use of an integrated platform, resilience.io, to deliver sustainable urban planning and inform decision making $[1,29,30]$. The platform is integrated with three sub-modules which are social-demographic forecasting model, agentbased model (ABM) and resource technology network (RTN) optimisation. The framework combines the functionality of the above three, allowing demand profiles simulation based on social-demographic scenarios, which in turn serves as groundwork for supply optimisation and planning [31]. Prior researchers have proved the effectiveness of this holistic methodology and platform in supporting resilient decision-making in the context of developing country. The modelling of urban energy system (UES), energy-water-food (EWF) nexus and waste-to-energy system by using resilient.io platform has been conducted and the Greater Accra Metropolitan Area (GAMA) of Ghana is used as the region of case study [1,29-32]. The results of these studies provide Ghana with various insights in the field of water supply, energy deployment and waste treatment. However, the model applicability demonstrated in these previous works are all founded on an identical context, the GAMA of Ghana. Depending on the urban planning progress of countries and regions, the ground-level formulation of model can be extremely different, entailing further case studies in an alternative context to demonstrate the robustness of resilience.io. In contrast to developing countries like Ghana, cities and regions of developed countries are often equipped with complete and functional infrastructure such as water and waste treatment facilities and their corresponding networks [33]. This would increase the complexity of system modelling as the baseline scenario must be prudently configured to reflect the supply-demand balancing of the existing system. Furthermore, developed countries are often subject to various policy constraints. For example, nuclear energy is banned in Australia due to its lack of public support, despite that about one-third of global uranium is deposited in the country [34,35]. These could partly explain why developed countries are rarely involved in the case study of system modelling research. Nonetheless, studies have shown the historical GHG contribution of developed countries takes about $60 \%$ from 1850 to 2005 [36], while in 2011, developed countries still contribute to $37 \%$ of global emission [37]. The statistics indicate the responsibility and need to reduce emission in developed countries, which can be accommodated by sustainable planning via system modelling, with another important performance indicator, financial feasibility, included in the matrix as well.

This paper seeks to address some of the aforementioned issues by presenting the system modelling of FEW2 nexus via resilience.io platform. Diverted from the previous work, a case study of developed country is discussed to showcase the FEW2 system modelling from another perspective. A scenario-based approach is highlighted in this work to address individual nodes in the nexus and assess prevalent policies. The results for water, energy and waste elements of FEW2 nexus are presented along the scenarios analysis. The production, consumption and environment impact of the food element is not included in this study, but it still participates significantly in the system level (e.g. post-consumer food waste, food manufacturing waste, a route for biosolids to serve food sector as fertilizers and reclaimed water for agricultural use). The food element has been addressed in a more thorough manner in our previous work by Bieber et al. [30]. The applicability of resilience.io platform in the context of developed country is also demonstrated in this study, where possible system solutions for Hunter Region in Australia are examined under several scenarios.

Hunter Region is Australia's largest region. With Newcastle's large metropolitan area on the Pacific coast, it resembles a microcosm of the broader Australian economy, with notable sectoral activities including food and energy production, natural resources and coal mining, defence industry, and service economies [38]. Water security remains a vital, strategic issue for the region, with water services in Lower Hunter undertaken through the public water authority, Hunter Water, which services nearly 600,000 users [39]. Although the region has significant groundwater resources, water supplies have, in the past, been vulnerable to drought events [40]. With increasing population levels forecasted, and a potential for decreased water yield with higher variability associated with climate change, Hunter Water and government agencies are considering a range of strategic options to address the region's water security over the medium and long term. Likewise, the region's projected population and industrial growth will result in an increase in water and energy consumption per capita. The Hunter Regional Plan 2036 calls for the diversification of the energy sector to take advantage of "the region's potential to be a major hub for next-generation power". Given agreements to increase the proportion of renewables in the energy matrix and two major coal-powered 
thermal power stations being scheduled to close in 2022 and 2035 (Liddell and Bayswater), the regional government promises to promote initiatives that can combine economic and energy diversification [41]. Waste-toEnergy is identified by local agencies as the most promising clean energy solution, as the increase of solid waste and wastewater generation also requires the region to expand its waste management capacity and upgrade its efficiency to reduce costs and meet climate targets [42].

To recover energy from various waste streams, anaerobic digestion (AD) of organic solid waste is a mature technology that plays a crucial role for its biogas (methane, $50-75 \%$ ) production and pathogen destruction characteristics [43]. It also minimises the residual solids for disposal and the odour of remaining putrescible substance [44]. In addition, co-digestion and thermal hydrolysis pre-treatments are interesting options to improve the yields of treating solid wastes and increase economic advantages [43]. AD and its variations are incorporated to the model in both centralised and decentralised scales to assess the feasibility of all the possibilities. Another waste degradation solution, gasification, is also demonstrated as one of the most efficient and eco-friendly technologies for waste-to-energy conversion [45]. Plasma and fluid-bed gasification are included in this model [46, 47]. The products of gasification processes are known as syngas. Syngas can be further upgraded through methanation process, where hydrogen reacts with carbon oxides to form methane and water [48]. Both syngas and biogas are modelled to go through pressure swing adsorption (PSA) process for purification and upgrading, so that they can be injected into gas grid for direct supply of energy [49]. PSA is selected amongst the $\mathrm{CO} 2$ capture processes because of its low energy requirements and low capital costs in comparison to common separation methods such as absorption and distillation [50]. The purified biogas and syngas are also modelled as fuel for combined heat and power generation. Such a combination of end-uses allows the model to allocate WtE technologies and gas-to-electricity conversion in the most efficient way based on the individual demand of gas and electricity.

The rest of the article is structured as follows. Section 2 first describe the overall modelling approach and case study model formulation, followed by the details of optimisation model. Section 3 mainly describes how the overall methodology is applied to Hunter Region in Australia to achieve the optimal FEW2 nexus especially in water, energy and waste sectors. This work includes the exploration of total five scenarios, namely "business as usual (BAU)", "water and wastewater", "Liddell and Bayswater power plant decommission", "waste-to-energy" and "policy interventions" (Fig. 2).

\section{Materials and methods}

This section describes the overall modelling framework used in this study as well as the main inputs and assumptions for the systems model implemented for the Hunter Region. Afterwards this model is applied to the case study under various scenarios.

\section{Resilience.lo modelling approach}

The resilience.io platform was developed to study urban or regional planning under a range of long-term scenarios. These scenarios can be designed to reflect policy changes, regional connections, economic background and advances in technologies, while providing insights on the optimal solutions of long-term development, that is, to meet local resource demands in a cost-effective and sustainable way [29]. The resilience.io platform provides the following three modules in series: sociodemographic model to forecast population and business development, agent-based model to simulate spatiotemporal activities and generate resource demands, and resource-technology-network optimisation to find a matrix of technologies with correct location and size, to meet all the demands [1]. The final goal is to plan investment and operational strategies based on economics metrics (e.g. capital expenditure, operating expenditure, taxes, etc) and environmental considerations (e.g. greenhouse gas emission), while connecting multiple levels in a system approach (Fig. 3). These modules can be used together to build a scenario, or they can be used independently, for example by supplying demand data from other sources as input to the optimisation module.

\section{Model for the hunter region}

To test the feasibility of studying the nexus between food, water, energy and (materials discarded as) waste for the Hunter Region with this platform, we have implemented a prototype model for the region. This model has been applied to demonstrate how the systems approach could be used to identify opportunities based on included material flows and conversion technologies. Resources and discarded materials (e.g. raw water, wastewater, municipal waste, etc) available are simulated or included from published data and regional forecasts, with specific technologies-with their economic and environmental performance-selected as input for the resource-technology-network optimisation model.

Using this approach, a first prototype model has been set up for the Hunter Region (Fig. 4) to simulate the current water demand, supply and networks and explore potential future designs and interventions to take advantage of synergies at the FEW2 nexus. Key resources that were incorporated in the model include potable water, non-drinking water (industrial use), source water, electricity, gas, domestic waste (municipal solid waste, 


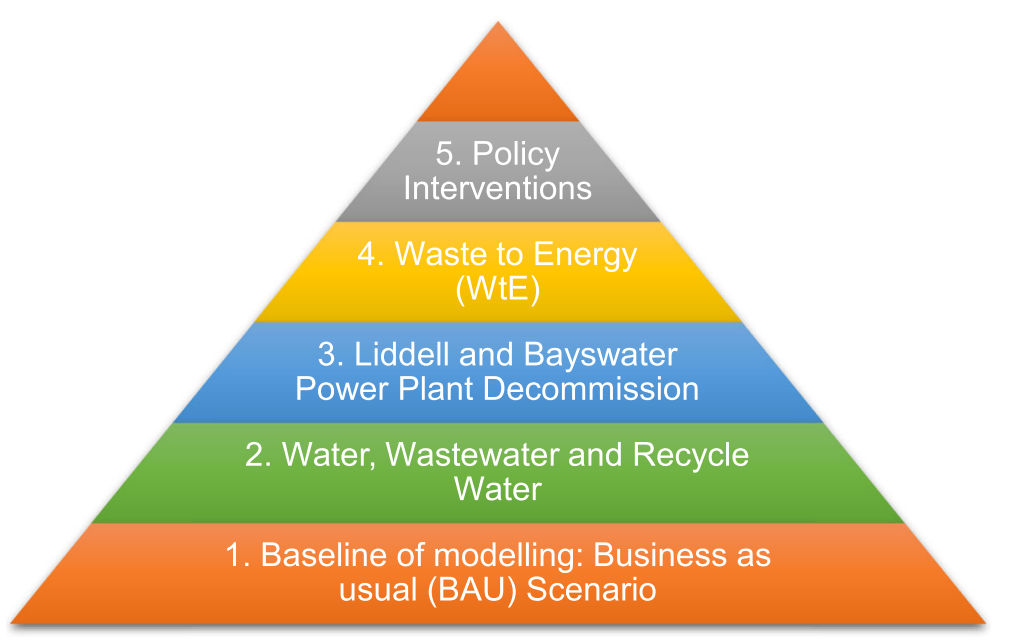

Fig. 2 The scenarios to be explored in this study

sewage), agricultural waste (manure, grape marc, etc) and other organic waste (food manufacturing waste, etc), biosolid, carbon dioxide, etc. Figure 5 shows example processes that could be set up in the model as process blocks to consider generation of energy from wastes. The combinations of feedstocks and technologies incorporated in this case study are listed in Table 3 with specific technologies that are incorporated in the model including both existing and potential new installations and conversion processes described in the waste-toenergy case study section. Amongst the products generated from the technologies, syngas is first simulated to undergo methanation process to convert it into methane and water. The upgraded syngas and biogas then enter PSA unit, where high quality methane is produced and used to supply gas demand (Fig. 5). The optimisation model selects which of these pathways can be most attractive from an economic and environmental perspective, under the constraints of land-use (e.g. land types and availability) and regional transportation (e.g. limited or costly resource sharing for non-adjacent areas). The results provide urban development plans for capital allocation on infrastructure and new technologies, as well as operation plans such as production rate and transportation rate schedules, in order to meet demands and minimise costs.

\section{Optimisation model structure}

To address the interrelationship of the nexus between food, water, energy and waste for the Hunter Region, the

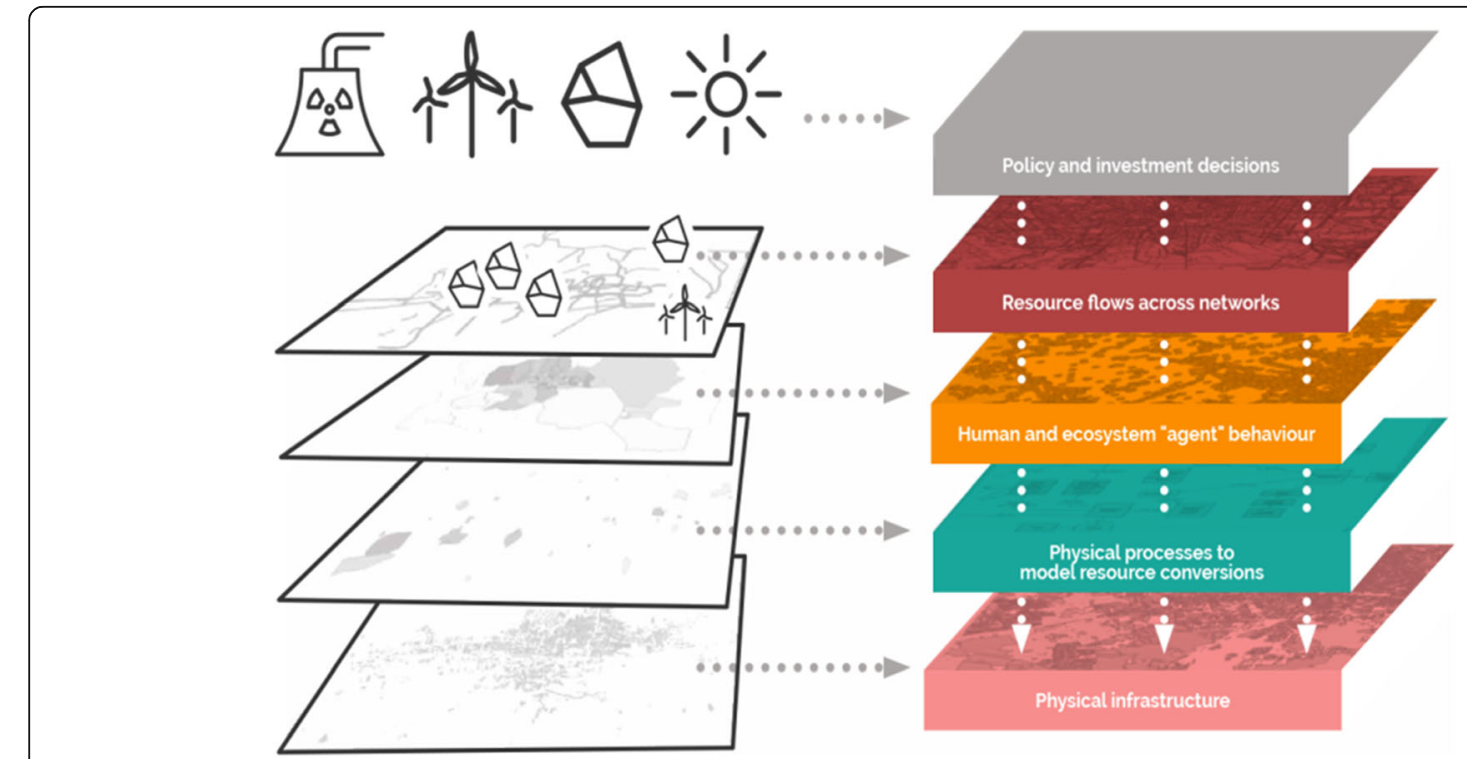

Fig. 3 Multiple layers included in the model [51] 


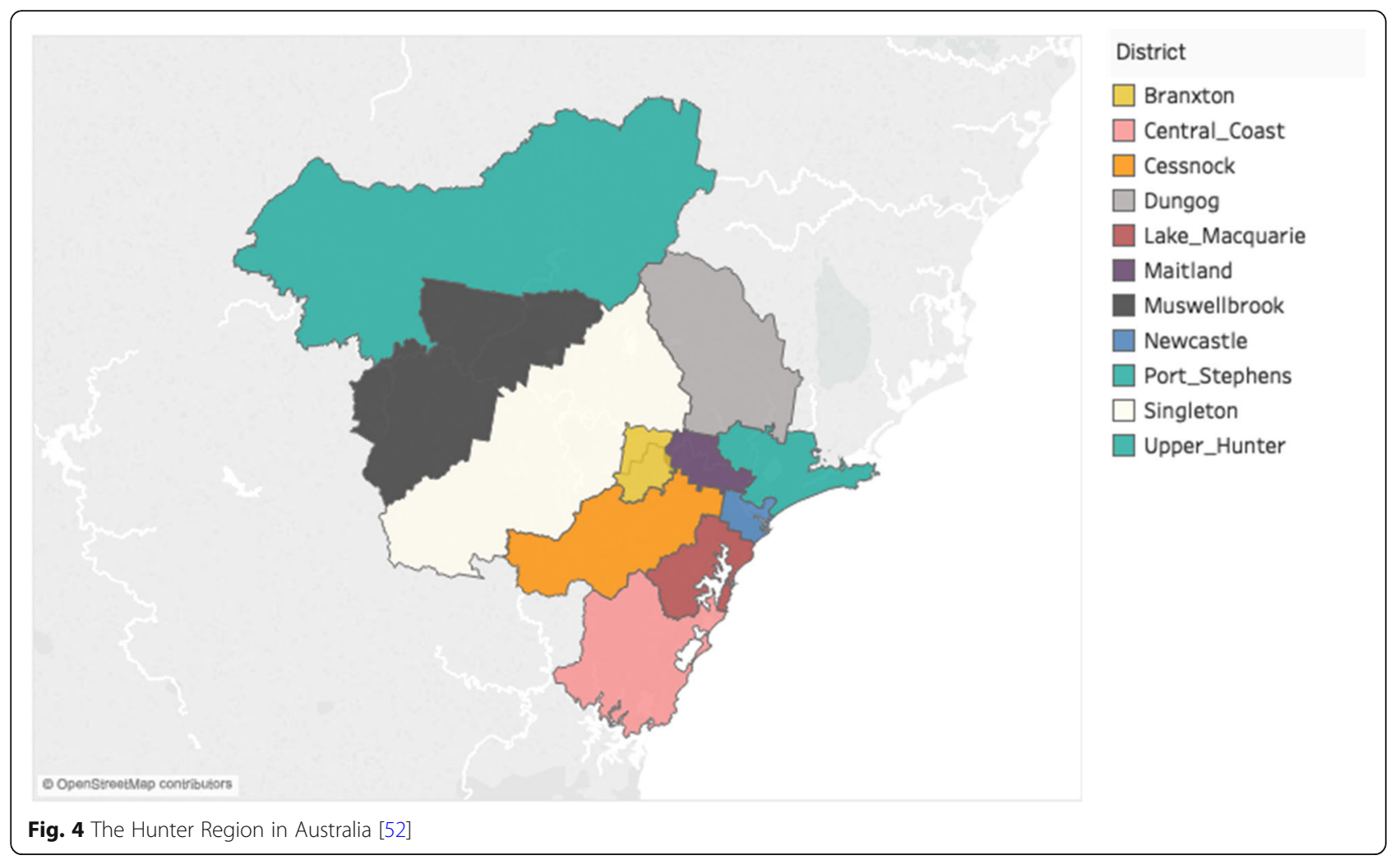

resource-technology-network optimisation model is formulated to reflect the resource flows as well as material and energy balance of conversion technologies. The optimisation problem is defined as a Mixed-Integer Linear Programming (MILP) model. The objective function is defined to be a weighted sum of capital expenditures, operating expenditures, and environmental impacts. In this demonstrative case study, greenhouse gas emissions are included as the only contributor to environmental costs, with its value monetised by carbon credit prices. Existing and new technologies are introduced as input- output flow vectors. Each technology entry is represented by an array of resources, waste, energy, labour and GHG emissions with their values normalised to facility capacity. Imports and exports are simulated in the entire system to accommodate various cross-boundary scenarios (e.g. Electricity generator supplying external demands, treated waste effluent discharged into rivers, and solid waste landfill). Model constraints can also be applied to restrict flows and define upper bounds for resource transportation. The model objective function is shown in Eq. (1) and the related constraints are also

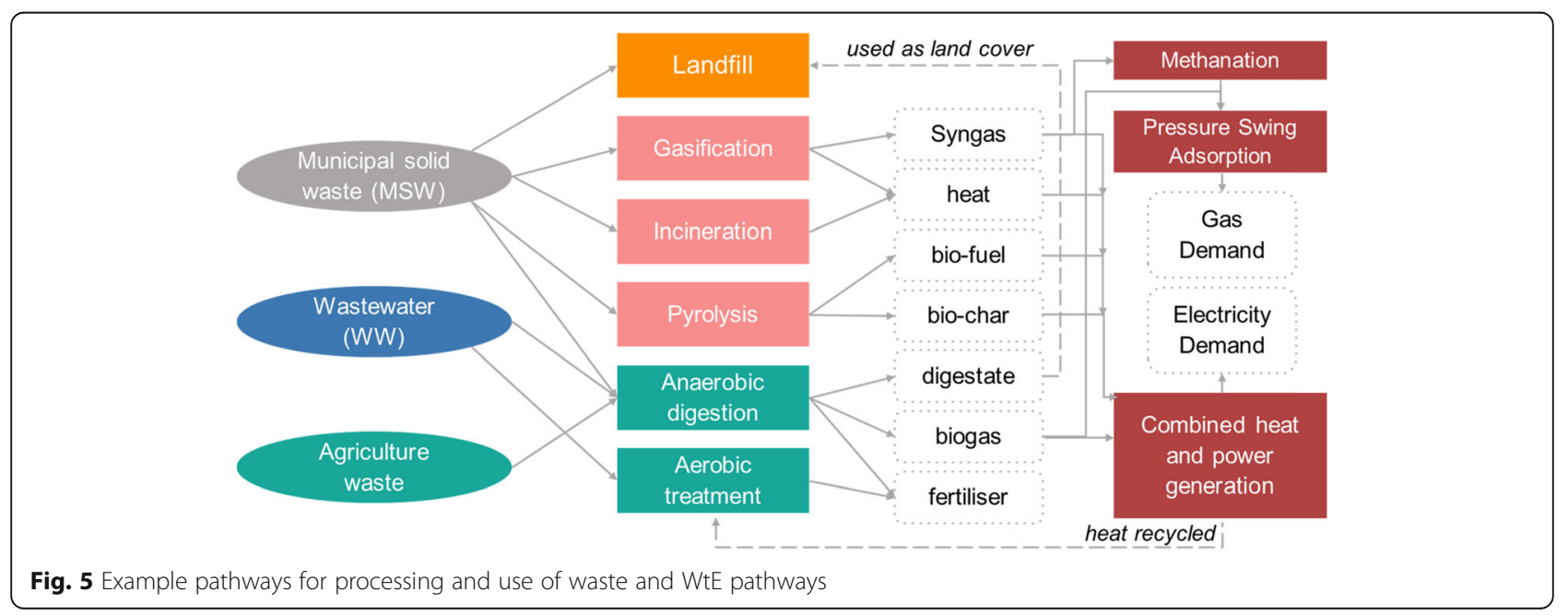


provided below. The corresponding nomenclature is summarised at the end of the paper.

Objective Function, $Z=\sum_{m, t m} \operatorname{ObjWt}(m, t m) \cdot V M(m, t m)$

$V M(m, t m)=\sum_{j, i} V I J(j, i, m) \cdot I N V(j, i, t m)$

$+\sum V P J(j, m) \cdot P(j, i, t, t m)$

$+\sum_{j, i^{\prime}, t}^{j, t} V Q(r, m) \cdot \operatorname{dist}\left(i, i^{\prime}\right) \cdot Q\left(r, i, i^{\prime}, t, t m\right) \cdot Y Q\left(r, i, i^{\prime}, t, t m\right)$

$+\sum_{r, i, t}^{r, i, i^{\prime}, t} V I(r, m) \cdot a b s(I M(r, i, t, t m)) \cdot Y I M(r, i, t, t m), \forall r, m, t m$

\section{Constraints:}

Technologies balances

$N(j, i, t m)=N(j, i, t m-1)+I N V(j, i, t m) \forall j, i, t m$

$$
\begin{aligned}
& \text { Flow constraints } \\
& \qquad Q\left(r, i, i^{\prime}, t, t m\right)-\frac{Q_{\max }}{(P H I(t) / 8760)} \cdot Y Q\left(r, i, i^{\prime}, t, t m\right) \leq 0 \forall r, j, i, t, t m
\end{aligned}
$$

Import/exportabs $(I M(r, i, t, t m))-I M_{\max } \cdot Y I M(r, i, t, t m) \leq 0 \forall r, j, i, t, t m$

$$
\begin{aligned}
& \text { Mass Balance, } R S(r, i, t, t m)=\sum_{j} M U(j, r) \cdot P(j, i, t, t m) \\
&+\sum_{i^{\prime}} Q\left(r, i, i^{\prime}, t, t m\right) \\
&-\sum_{i^{\prime}} Q\left(r, i^{\prime}, i, t, t m\right) \\
&+ I M(r, i, t, t m) \forall r, i, t, t m
\end{aligned}
$$

As shown in above equations, the objective function is a weighted average of metrics $(\mathrm{m})$ including capital investment (VIJ), operating costs (VPJ), resource transportation (VQ) and resource import/export costs of resources (VI). The optimisation model also implements various constraints to model restriction encountered in urban planning. Technology constraints are imposed to record the number of technology investment along each time period. Material and energy balance constraints are introduced to match demand value at each time period and spatial zone. Flow limits for waste transportation, water pipes and electricity grid delivery are also imposed. Import and export limits can be applied to simulate resource shortage scenarios (e.g. water shortage in section 3.3). Besides single period planning, the model output of a time period serves as the input of the next period. Together with the evolution of population status and demand behaviours predicted in forecasting model, optimisation process for 20 years is iterated to achieve future planning at future conditions.
A series of different software tools were employed to set up the optimisation program, including YAML data serialisation language for input/output of parameter data, open-source GUN Linear Programming Kit (GLPK) for solving the MILP optimisation problem, Java 8 to code the overall RTN module and R for visualising optimisation outputs.

The five scenarios explored in this study covers slightly different sets of technologies and resources, with total of 29 candidate technologies, 11 existing technologies, 12 resources, 8 regions and 5 time periods. Part A to G in the Additional file 1 list the key input data, running time and detailed assumptions applied in the modelling, together with the data sources used in this study.

\section{Results and discussion}

This section describes the five scenarios explored in this study, using the systems model for the Hunter region described above. Each scenario is considered at the current situation (based on 2016 data as a baseline) as well as forecasts at 5-year intervals until 2036 following the timeline of the 20-year regional blueprint published by the NSW government. The FEW2 nexus has been built up via scenario analysis and each scenario presents the system from the perspective of either water and wastewater, energy, waste or system-wise performance.

\section{Scenarios explored in this study}

1. Business-as-usual (BAU); a baseline scenario using the current infrastructure in the region for water and energy (electricity and gas),

2. Water and wastewater scenario, which includes introduction of new technology, e.g. water reclamation, and constraints on the use of raw source water,

3. Closure of the coal-fired Liddell and Bayswater power stations in the near future, following Hunter Regional Plan 2036,

4. Waste to energy scenario (WtE), in which biosolids, municipal solid wastes, agricultural wastes and other organic wastes are considered as the (co-)feedstock of renewable energy generation using anaerobic digestion (with thermal hydrolysis), incineration, gasification and pyrolysis, and

5. Economic/policy scenarios, including changes of feed-in-tariffs and carbon credit to study the sensitivities of waste-to-energy.

\section{Business as usual (BAU) scenario}

Business as usual (BAU) scenario serves as a basis to analyse the changes in other scenarios. The current network for potable water production and wastewater treatment is established in this scenario. Power stations 
inside Hunter Region (Eraring and Vales Point) are modelled to supply all the electricity demand in 2016 [53]. As Hunter Region is a net producer of electricity, the power stations are also responsible for other regions in Australia. The model limits $10 \%$ capacity of the local electricity generators to use for local consumption. The rest is modelled to leave the system to support regions outside the study area. This is based on the electricity demand (414 MW) [53] and total generator capacity (4200 MW) [54] of Hunter Region in 2016. The existing facilities will be carried out to other scenarios as necessary constituents of FEW2 nexus. Details of existing facilities can be found in Additional file 1: Part E.

In terms of waste management, biosolids management cost is modelled by referencing BAU options provided by GHD Pty Ltd. [55], where five aerobic digestors are scheduled in 2030 to accommodate the increase in wastewater generation. The input solid waste streams are assumed to leave the system through recycle/recovery and landfill at different prices. The biosolids disposal cost via land application program is included in the system, based on cost data provided by Hunter Water [56]. Other than biosolids, the landfill levy of MSW is $\$ 78.20$ dollar per tonne [57]. For other organic feedstocks, depending on the feedstock types, waste processing facilities are available locally according to MRA Consulting Group [58]. Organic wastes are mostly processed to make compost or used as animal feed, either on site at waste production facility or nearby farms through local arrangements. A gate fee is often charged by waste processers from waste producers to offset the cost of operating the site. Similar to landfill levy, gate fees will be incurred for organic wastes if they are to leave the system without further processing. This is specified by the cost associated with material export in the optimisation model. The assumptions for gate fees of various feedstocks are listed in Table 1.

The results of business as usual scenario show that no additional investment is needed to supply various resource demand in the Hunter Region, except for potential pipeline network construction during certain time intervals. Current infrastructure planning is more than sufficient to satisfy $100 \%$ demand. However, since no WtE treatment facilities are present, disposal of waste incurs operating cost of the system.

Table 1 Feedstock gate fee or landfill price (AUD) [57]

\begin{tabular}{ll}
\hline MSW - Landfill & $\$ 78.20$ \\
Forestry & $\$ 78.20$ \\
Commercial and Industrial & $\$ 135.70$ \\
Post-consumer food waste & $\$ 78.20$ \\
Manure & $\$ 25$ \\
Other organic wastes & $\$ 10$ \\
\hline
\end{tabular}

GHG emission exhibits steady growth from 2016 to 2036, mainly because the demand profile increases across intervals. A higher capacity for various existing facilities is required to satisfy all the demand. Figure 6 displays the GHG emission for BAU. Note that the values include all the existing facilities of water and wastewater treatment, power stations, etc.

The capital expenditure (CAPEX) and operating expenditure (OPEX) are shown in Table 2. The CAPEX value includes the construction cost of additional water and wastewater network required, as well as the capital cost of five aerobic digestors evaluated by GHD Pty Ltd. [55]. The present value of cost is extracted from the background facilities (including existing water treatment plants and power stations) to compare with WtE scenarios. The values are summarised in Table 2 .

\section{Water and wastewater scenario}

This scenario extends the BAU scenario and presents the modelled FEW2 nexus from the perspective of water and wastewater. In BAU, the results show no investment is compulsory to satisfy regional water demand and wastewater treatment capacity from 2016 to 2036, which is based on an implicit assumption that raw source water resource can be extracted without a limit for drinking water production. The assumption is valid in most situations, considering the sub-tropical climate in Hunter, with annual rainfall at about $870 \mathrm{~mm}$ across the region [59]. Nonetheless, according to Hunter Water, the level of water storage dams responsible for the region decreases faster than usual during hot, dry season due to relatively high evaporation rates and shallow dam storages [60]. Figure 7 taken from Hunter Water shows the forecasting of storage levels under three scenarios, as well as the situations when water restrictions may apply.

The water storage outlook indicates that dam level will decrease to $60 \%$ of total storage and hit level 1 water restrictions under low rainfall scenario at July of 2019. Level 1 restrictions refers to forbidden sprinkler use for household and business users [61]. In this scenario, the critical water shortage level caused by unprecedented drought conditions is simulated in the model. Constraints are set to limit the extraction of raw water to ensure at least $60 \%$ of total dam storage. A set of options for water supply is included in this analysis such as water reclamation technology, desalination and water import.

NEWater, initiated by Singapore's Public Utilities Board (PUB), is modelled as one of the water reclamation technologies in this study. Started in 1970s, the NEWater technology currently supplies up to $40 \%$ of Singapore water demand. NEWater plants collect treated wastewater from standard reclamation facilities and apply 3-step treatment to upgrade the water quality. 


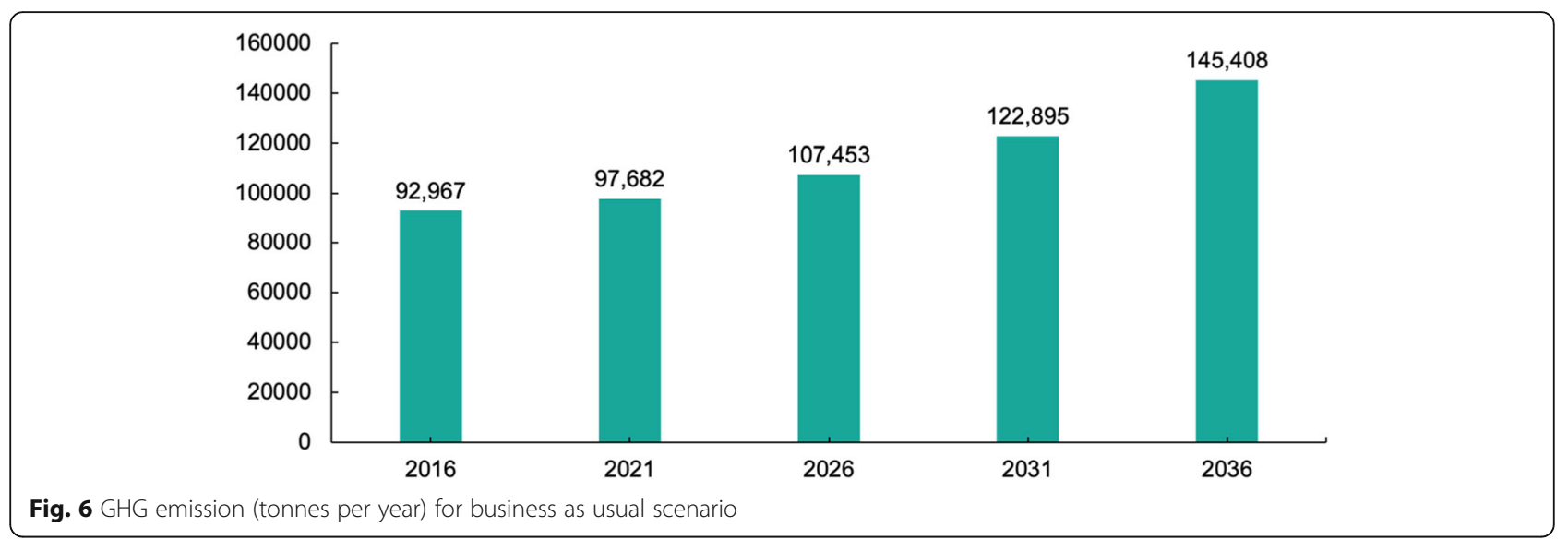

This includes microfiltration to filter out microscopic particles, reverse osmosis to remove undesirable contaminants and ultraviolet disinfection to eradicate any residual organisms [62]. The produced water is sent for non-portable use (e.g. industrial use and air-con cooling) and non-direct portable use at dry seasons (i.e. blending with raw water in reservoir). Compared to other water reclamation designs, NEWater should thus be considered as a more reliable solution for drought conditions in Hunter Region for its wide applicability and proven reliability. It is thus configured in the model to produce both raw water and non-drinking water. Another option, desalination, is also included to produce drinking water directly. Together with water import, the optimisation model evaluates the economic and environmental performance of all options to provide the best combination.

The results indicate NEWater outperforms desalination and other options as it provides raw water to maximise the capacity of existing water treatment plant and delivers non-drinking water for industrial and agricultural use at the same time. Desalination and raw water import are not favoured by the model for their relatively high operating costs or prices. Figure 8 shows the production rate of NEWater and recycled water to wastewater ratio over 20 years. About $35 \%$ of wastewater need to be recycled in 2036 to prevent the dam level from falling below $60 \%$ at extremely drought periods in Hunter. To achieve this objective, three 15,000 $\mathrm{m}^{3}$ per day NEWater plants need to be allocated in Port Stephens (2) and Dungog (1), amounting to a total CAPEX of 562 million AUD, which also includes the capital cost of additional wastewater pipeline connection. The proposed investment also incurs 11 million AUD annual operating costs and 54,000 t of GHG emissions. The jobs created to operate such facilities are 78 Full Time Equivalent (FTE) positions. Under the constraint of raw source water extraction, residential water demands, and industrial water demands, including those from energy sector, are all met accordingly with drinking water or non-drinking water (drinking water can be converted to non-drinking water in the model, but the reverse is forbidden). The model signals the investment of NEWater, but the actual capacity and location of investment are still subject to the possibility of extremely droughts across the region, practicability of pipeline construction, etc.

\section{Liddell and Bayswater power plant decommission scenario}

The Hunter's affluent coal storage and developed coal mining industry boost its economy and makes it the energy hub of the New South Wales (NSW) [63]. Four coal-fired power plants are located across the region, generating $8840 \mathrm{MW}$ electricity and accounting for $44 \%$ power generation in NSW [41]. Nonetheless, Sustainable Development Goals (SDG) indicator 7.1 aims for sustainable energy security: "By 2036, ensure universal access to affordable, reliable and modern energy services" [64]. The NSW government has set an aspirational goal to achieve net-zero emissions by 2050 [65]. The local policies of the Hunter also echo this ambitious goal. The Hunter Regional Plan 2036 calls for the diversification of the energy sector to take advantage of "the region's potential to be a major hub for next-generation power". The regional government promises to promote initiatives that can combine economic and energy diversification, with two major coal-powered thermal power stations being scheduled to close in 2022 and 2035

Table 2 BAU performance indicators in year 2036

\begin{tabular}{llll}
\hline CAPEX & OPEX & Present Value of Cost (7\% discount rate over 20 years) & GHG Emissions \\
\hline 228 million AUD & 38 million AUD per annum & 370 million AUD & $145,400 t$ per annum \\
\hline
\end{tabular}




\section{Hunter Water Storage and Outlook}

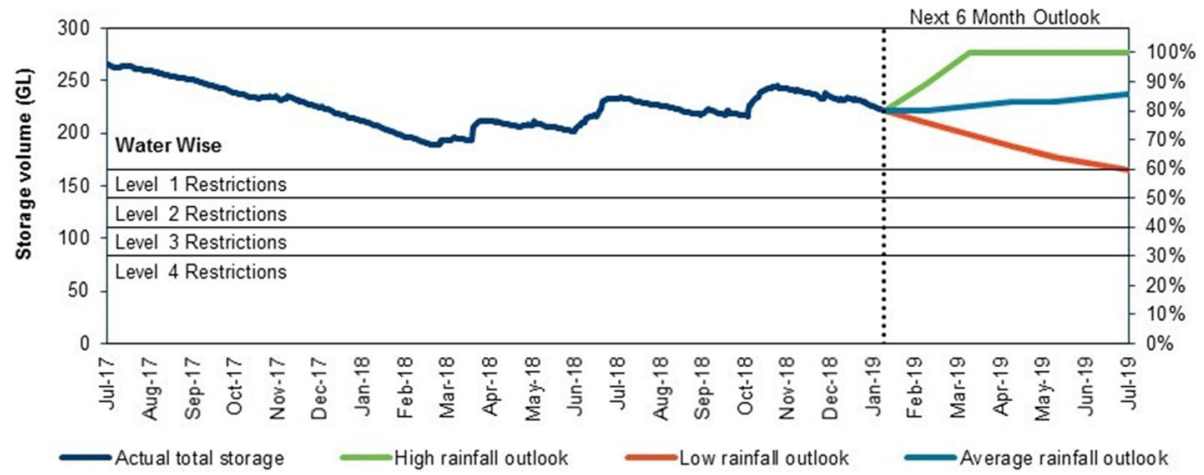

Fig. 7 Hunter Water Storage and Outlook from July 2017 to July 2019 [60]

(Liddell and Bayswater) [41]. The capacity of Liddell and Bayswater power plants is $2000 \mathrm{MW}$ and $2640 \mathrm{MW}$ respectively, amounting to $52 \%$ of the region's total power generation. Based on the current electricity demand in Hunter Region, 200 MW and 264 MW vacancy of energy need to be filled in 2022 and 2035 respectively. Since the model uses 5 years as interval from 2016 to 2036, 2022 and 2035 are rounded to 2021 and 2036 respectively to simulate the plummet in electricity supply. With a total of 13 types of green technologies assessed in the resource-technology network, the resilience.io platform can provide a high-level optimisation of available options and signal the potential plan with minimised costs and GHG emissions.

With investment on the presented matrix of technologies, the electricity demand of all citizens can be met at both 2021 and 2036 across the region. The accumulated CAPEX to achieve the objective is 4.52 billion AUD at 2021 and 10.8 billion AUD at 2036. The associated annual OPEX is 91.2 million AUD at 2021 and 218 million AUD at 2036. With proposed clean energy scheme, the
GHG reduction that can be achieved from 2016 level is $22.7 \%$ at 2021 and $53.3 \%$ at 2036 . Figure 9 shows the optimal energy structures provided by the model in both 2021 and 2036. It is evident that solar panels, combined cycle gas turbine with carbon capture and storage (CCGT-CCS) and onshore wind energy conversion systems are most recommended by the model, due to their relatively low GHG emissions or low costs. Small-scaled biofuel and hydro power plants accounts for 11.6 and $10.6 \%$ of total clean energy facilities, suggesting the feasibility of decentralised distribution for such technologies in various regions. In addition, a total of 784 FTE jobs are created to support the operation of invested facilities.

\section{Waste-to-energy (WtE) scenario}

In this scenario, a high-level optimisation of WtE technologies in 2036 is provided. The optimal strategies are evaluated in the context of business as usual scenario. Biosolid, municipal solid waste, agricultural waste and other organic waste within the study area are considered

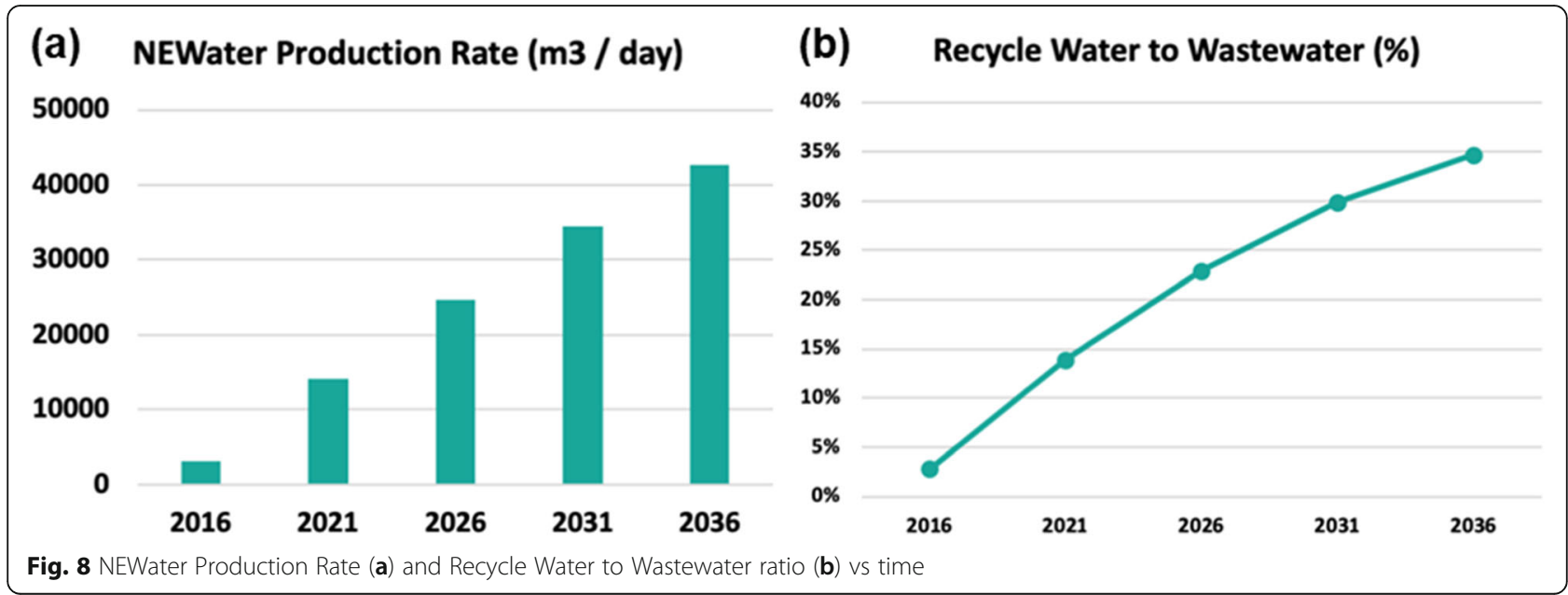




\section{(a) 2021 Energy Structure}

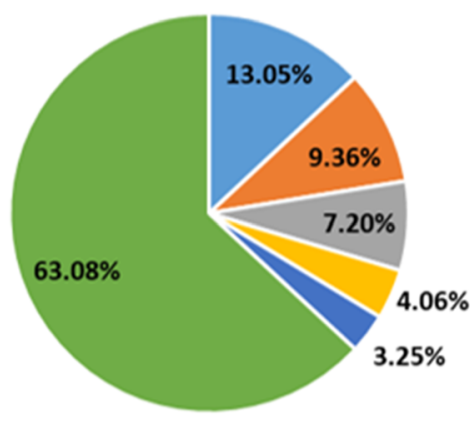

After closure of Liddell power plant (b) 2036 Energy Structure
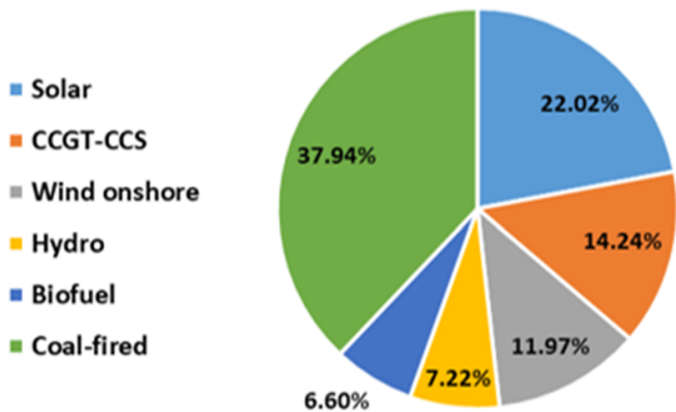

$6.60 \%$
" CCGT-CCS

= Wind onshore

" Biofuel

= Hydro

= Coal-fired

\section{After closure of Bayswater power plant}

Fig. 9 Model-suggested optimal energy structure in 2021 (a) and 2036 (b) (by energy generation capacity)

as (co-)feedstocks of renewable energy generation. Their spatial distribution lays the foundation of quantifying energy potential to be recovered from several WtE pathways [1]. A total of 19 combinations of technologies and feedstocks, including biochemical and thermochemical technologies (anaerobic digestion with thermal options and gasification) are modelled in the resourcetechnology network of resilience.io. Compared with traditional landfills, they are viewed as 'green' candidates to complete the WtE pathway. Table 3 also shows the details of evaluated technologies in terms of modelling inputs.

Both biogas and electricity are generated as the output resources of various anaerobic digestion (AD) technologies. Within the context of this study, the (co-)digestion of various feedstocks is evaluated. Thermal hydrolysis option (AD-THP) is also included in the model as promising extension of AD [43]. Both syngas and electricity can be generated as the output of fluid-bed or plasma gasification technologies, which operates at high temperature above $750{ }^{\circ} \mathrm{C}$ to convert organic waste into syngas, comprising hydrogen, carbon monoxide and

Table 3 Waste treatment and recovery technologies in modelling

\begin{tabular}{ll}
\hline Technology Category & Waste Streams (Input) \\
\hline Large AD with THP & Biosolids, MSW, Agricultural and other waste \\
Large AD & Biosolids, MSW, Agricultural and other waste \\
Farm AD & Biosolids, MSW, Agricultural and other waste \\
Large AD co-digestion & Biosolids, MSW \\
Plasma gasification & Biosolids, MSW, Agricultural and other waste \\
Fluid-bed gasification & Biosolids, MSW, Agricultural and other waste \\
Incineration & Biosolids, MSW, Agricultural and other waste \\
Pyrolysis & Biosolids, MSW, Agricultural and other waste \\
\hline
\end{tabular}

usually carbon dioxide. Syngas can be further upgraded through methanation process, where hydrogen reacts with carbon oxides to form methane and water [48]. Biogas and syngas can then undergo pressure adsorption swing purification for upgrading to natural gas quality [49]. Electricity and biogas/syngas generated are used to support energy network by feeding into either electricity or gas grid to fulfil corresponding demand (if any). In addition to the common centralised facilities, technologies with decentralised features are also incorporated in the model to evaluate the feasibility of both options in a systematic approach. Solid organic wastes are also allowed to be transported by truck from region to region, which opens up flexibility for centralised waste treatment by considering feedstocks as well as demands in a holistic way. The model simulation and optimisation start from year 2016 where no WtE facility is installed. With 5-year intervals, the model progressively suggests optimal WtE strategies up to 2036 based on both economic incentives and spatial-temporal constraints (land use, labour hour, etc). The results are presented for biosolids, municipal solid waste, agricultural waste and other organic waste.

\section{Biosolids}

Figure 10 summarises the biosolids $\mathrm{WtE}$ facility treatment rate, energy production rate and number of installations by regions and types of technology. The transportation of biosolids is also included.

Four biosolids WtE options have been selected by the model at the timestamp of 2036. Plasma gasification with MSW as co-feedstocks (plasma), AD with thermal hydrolysis (AD-THP) and AD with MSW and wastewater as co-feedstocks (AD-co) are favoured by the model based on the objective function and defined economic and environmental performance indicators (see 

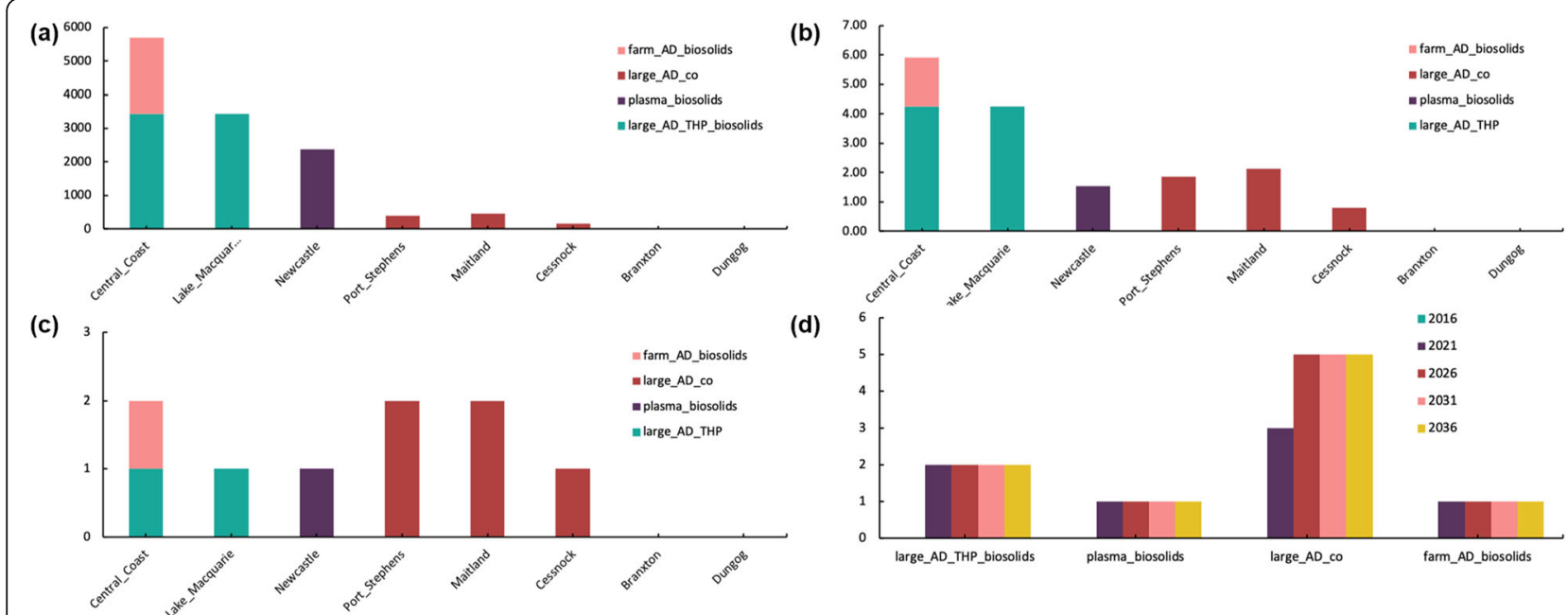

Fig. 10 a Biosolids Treatment Rate 2036 (tonnes per year). b Biosolids WtE energy generation 2036 (Total: 16.5 GWh). (c) Number of biosolids WtE facility Installation by district 2036. (d) Number of biosolids WtE facility Installation as time progresses

Additional file 1: Part A Table S3). Pyrolysis and incineration of biosolids are eliminated by the model. The reason is presumed to be their inefficient conversion in generating renewable energy. $16.5 \mathrm{GWh}$ per annum of energy can be generated from biosolids mainly in the form of biogas or syngas, which amounts to $5.1 \mathrm{GWh}$ of electricity. This can be used to reduce Hunter Water's wastewater treatment energy consumption by $\sim 16 \%$. Two centralised AD-THP are suggested by the model in Central Coast and Lake Macquarie respectively to treat biosolids only, accounting for $\sim 70 \%$ of total biosolids in the study area. They are selected due to their relatively low costs. Plasma gasification are proposed to treat $8.6 \mathrm{t}$ per day biosolids together with municipal waste generated in or transported to Newcastle. The plasma plant is mainly used for municipal waste treatment, but the remaining capacity of the facility is further utilised for biosolids WtE processing. AD co-digestion of MSW with biosolids are also proposed in Port Stephens, Maitland and Cessnock. The plants treat most of the MSW in the corresponding region and handle a smaller portion of local biosolids. The remaining biosolids will be transported to Newcastle for centralised plasma gasification treatment. A farm AD plant is also allocated in Central Coast to recover energy from the remaining biosolids that will not be treated by the centralised AD-THP. This shows that the model only selects decentralised facilities when centralised plants cannot treat all the waste in a region.

\section{Municipal solid waste}

The results for MSW treatment planning are summarised in Fig. 11. Similar to the biosolids results, pyrolysis and incineration are not selected by the model.
Between two gasification options, plasma technology outperforms fluid-bed gasification for its lower cost per unit energy generation. As illustrated in Fig. 11d, the geographic centrality of Newcastle in the study area is recognised by the model. Two centralised gasification plants are planned in Newcastle, which treat most municipal waste from Newcastle, Maitland, Port Stephens and Lake Macquarie, accounting about 50\% of MSW generated in the study area. Investing the high capacity facilities in Newcastle minimises the transport costs of MSW from other regions. AD with municipal waste and liquid waste as co-feedstock (AD-co) is planned in Port Stephens, Maitland and Cessnock. No WtE facility is allocated for both Dungog and Branxton, whose MSW will be transported to Maitland or Port Stephens for treatment. Central Coast will be able to digest $124 \mathrm{t}$ per day of its own municipal waste in 2036 with AD-THP for MSW and decentralised farm AD. A small amount of waste is transported to Lake Macquarie to fill the remaining capacity. By processing biosolids and MSW, $178 \mathrm{GWh}$ of biogas/electricity is produced, amounting to $55.2 \mathrm{GWh}$ electricity. This can support about $60 \%$ of total electricity consumption by Hunter Water.

\section{Agricultural and other organic waste}

Agricultural and other organic waste feedstocks can contribute up to $80 \%$ of total WtE energy generated, as they are the largest source of feedstocks in the studied area. The results are summarised in Fig. 12. Decentralised digestion plant is most favoured by the model with no transportation across the regions (Fig. 12d). This is mainly due to the large quantity of agricultural available feedstocks, as well as the decentralised nature of agricultural waste distribution. Transportation becomes less 


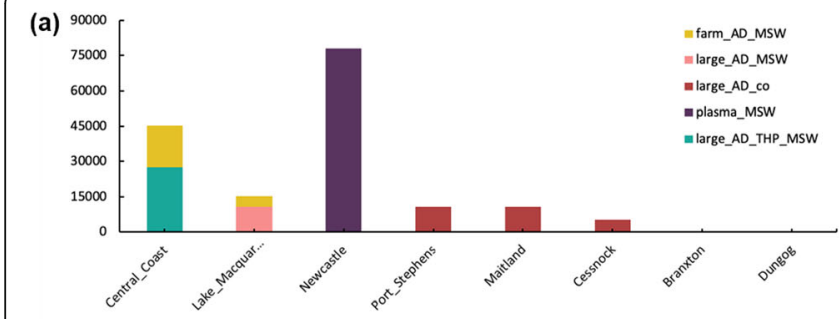

(c)

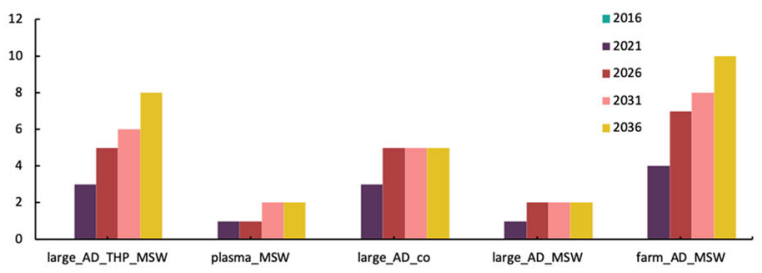

(b)

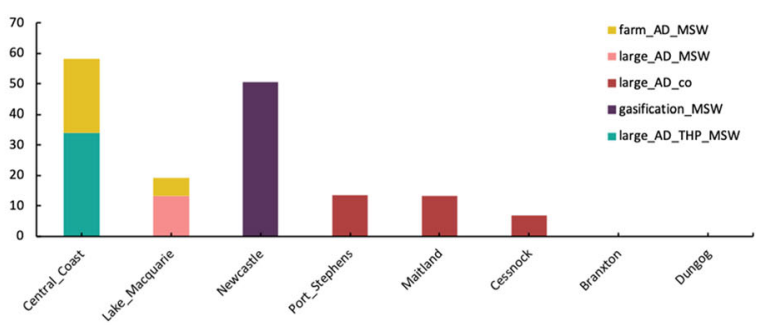

(d)

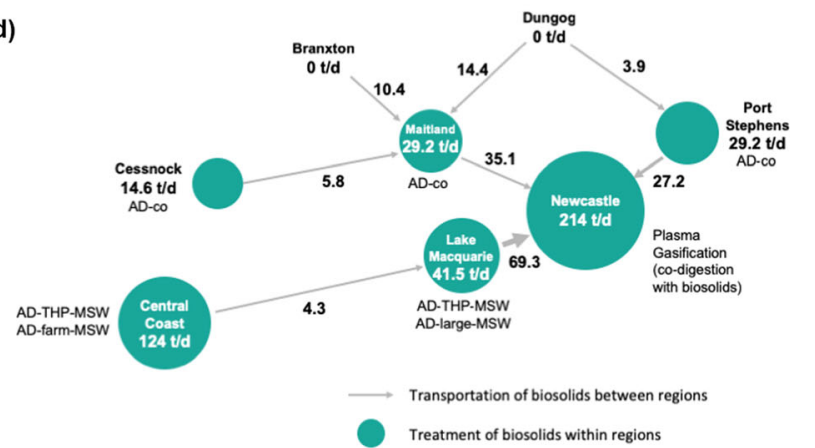

Fig. 11 a MSW Treatment Rate 2036 (tonnes per year). b MSW WtE energy generation 2036 (Total: 162 GWh) (c) Number of MSW WtE facility Installation 2036. d Transportation of MSW per district (tonnes per day)

cost-effective for large organic mass. A combined approximately $854 \mathrm{GWh}$ energy can be generated and used by injecting into grid. $94 \%$ of the energy is in gas form and the rest is electricity.

In 2036, zones cannot reach $100 \%$ of WtE conversion due to excessive amount of organic feedstock identified in the region (Fig. 13). Due to its relatively high waste generation, Central Coast treats only $28 \%$ under the spatial-temporal constraints included the model (land use, labour hour, etc). Newcastle and Cessnock are well above average due to the installed gasification and $\mathrm{AD}$ -
THP facilities. The remaining regions recover about half amount of identified waste. The rest of the waste can only be landfilled or recycled by existing waste processors in the model, incurring potential energy debit and certain gate fees.

\section{WtE performance indicators}

This section presents various performance indicators for the model suggested WtE strategy at 2036, including CAPEX, OPEX, present values (PV), GHG emissions, etc. (Table 4). The last column in the table compares

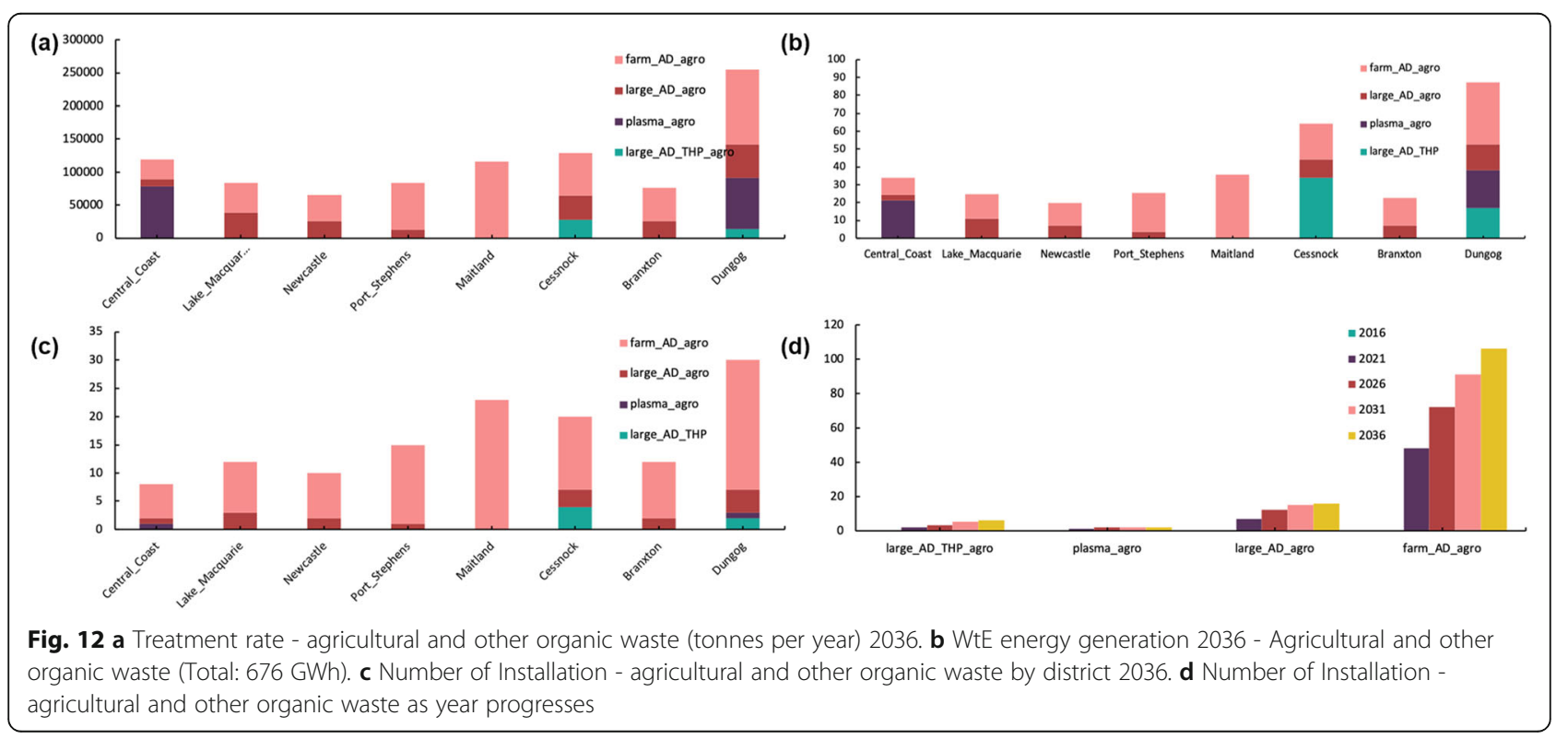




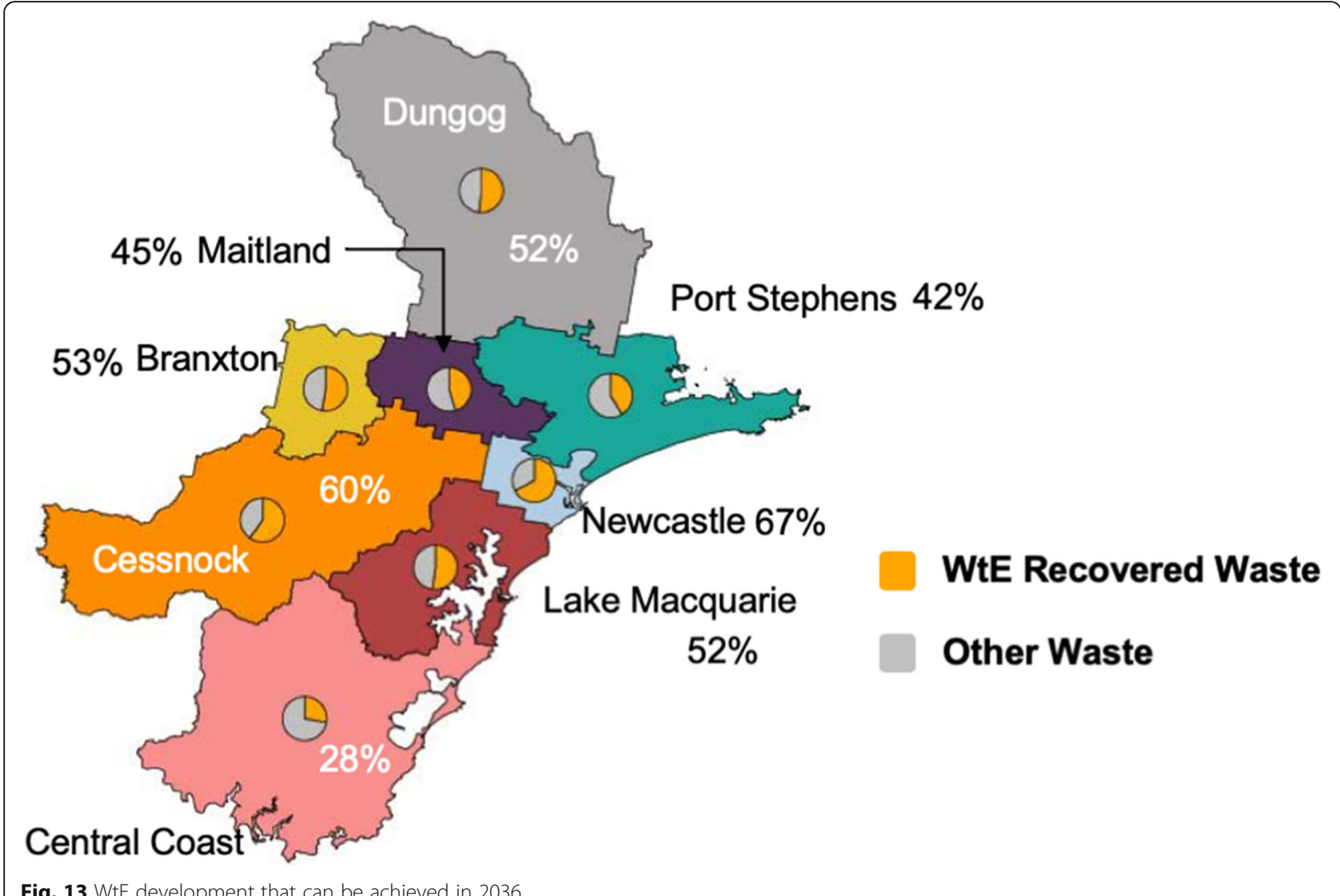

Fig. 13 WtE development that can be achieved in 2036

WtE scenario with BAU from each type of feedstock. The WtE technologies manage to reduce waste management cost, avoid landfill levy and reduce gate fees. The electricity and gas produced by WtE facilities are used to supply energy demand, but the equivalent earnings of energy should be calculated to show the economic benefits. In the last column of Table 4, the potential landfill levy and gate fee savings for waste disposal are displayed in totality of present values from 2016 to 2036. Similarly, the equivalent revenue of energy generated is also calculated in present value to show the financial drivers behind the model results. The assumptions for present value analysis are included in Additional file 1: SI part G.
For biosolids treatments, slight reduction of GHG emissions is observed when compared with BAU scenarios. This is contributed by the reduced electricity consumption for background facilities (wastewater and water treatment, etc). Besides the economic and environmental indicators stated above, a total of 72 FTE jobs are required to operate the allocated biosolids WtE units. This reveals that WtE installations also support economic activity in the region by creating new jobs. Compared to business as usual scenario, a present value saving in the order of $\$ 91 \mathrm{~m}$ over 20 years can be achieved, which is the main driver of biosolids WtE optimisation. The transportation and reuse of biosolids can also be avoided in a scale of

Table 4 Summary and comparison of the BAU scenario with other scenarios in Section 3.5

\begin{tabular}{|c|c|c|c|c|c|}
\hline & \multirow{2}{*}{$\begin{array}{l}\text { CAPEX (million } \\
\text { AUD) }\end{array}$} & \multirow{2}{*}{$\begin{array}{l}\text { OPEX (million } \\
\text { AUD per annum) }\end{array}$} & \multirow{2}{*}{$\begin{array}{l}\text { Cost PV (million } \\
\text { AUD) })^{\mathrm{a}}\end{array}$} & \multicolumn{2}{|l|}{ Compared to BAU } \\
\hline & & & & $\begin{array}{l}\text { PV of avoided costs from } \\
\text { BAU (million AUD) }\end{array}$ & $\begin{array}{l}\text { PV of equivalent revenue of } \\
\text { generated energy (million AUD) }\end{array}$ \\
\hline BAU & 228 & 38 & 370 & - & - \\
\hline Biosolids & 150 & 6.6 & 279 & 33.2 (management cost) & 9.22 \\
\hline MSW & 136 & 5.6 & 98.3 & 28.3 (landfill levy) & 89.8 \\
\hline $\begin{array}{l}\text { Agricultural \& other } \\
\text { organic Waste }\end{array}$ & 258 & 10.7 & 173 & 44.4 (landfill or gate fee) & 146 \\
\hline
\end{tabular}


present value $\$ 33.2 \mathrm{~m}$, as biosolids are consumed in WtE facilities. Municipal solid waste present value figures reveal that the high landfill levy rate and high efficiency of renewable energy generation drive the model to optimise the MSW treatment as much as possible. For agricultural and other organic wastes, the generated energy, mainly presented in the form of upgraded biogas or syngas, can be very competitive to imported natural gas or electricity, which is the main driver of optimisation.

\section{Policy intervention scenarios}

Decision makers face political challenges or encounter other key considerations that encourage or penalise certain technologies or resources. The economic and environmental sensitivity of WtE modelling should be evaluated. Carbon pricing scheme was introduced to Australian industrial sector from 2012 with a cost of $\$ 23$ per tonne of emitted carbon dioxide, which was abolished later in 2014 [66]. The World Bank also proposed that price levels of US\$30-100 per tonne to decarbonise the energy sectors [67]. In this scenario, the carbon credit prices are set as alternatively $\$ 0$, $\$ 25, \$ 75$ or $\$ 125$ (AUD) per tonne to study its effects on the three key indicators: CAPEX, OPEX and GHG emissions (Fig. 14). The increase in carbon price is achieved by increasing the weighting of GHG emission in the overall RTN optimisation. The levels of prices are referred to as low, medium and high price respectively. The below CAPEX and OPEX figures only consider WtE technologies. GHG emissions include WtE, landfill and other energy generation sectors to demonstrate the impact of carbon price in the entire energy sector.

Based on the model, a higher carbon price can effectively accelerate the transition of energy structure towards a low-carbon direction. More WtE productions are favoured by the model considering that less electricity demand from power station reduces carbon emissions significantly. This results in different levels of increases in both CAPEX and OPEX under various carbon prices. Besides WtE technologies, higher carbon price also boosts the installation of renewable energy technologies such as solar panel, wind farm, hydroelectricity plant, etc. They substitute part of coal-fired power stations, but with much lower emissions. Under this scenario, a high carbon credit price (125 dollar) can thus reduce the carbon emission by about $21 \%$ in the entire system with $8.1 \%$ of increased capital cost.

Feed-in tariff (FIT) is another common policy intervention in energy sector. Similar to carbon price, FIT was once introduced by New South Wales government in 2009 at $\$ 0.60$ per $\mathrm{kWh}$ and revoked in 2011 [68]. In this scenario, FIT of 60 cents per kWh for electricity and $\$ 0.20$ per $\mathrm{kWh}$ for gas are applied. The different tariffs for electricity and gas are designed to account for the conversion efficiency from electricity to gas as well as the cost of upgrading biogas.

Figure 15 shows that CAPEX of WtE will increase by $16.3 \%$ due to the increased installation. Operating cost of WtE will be significantly reduced after accounting for the FIT. The carbon emission in the entire system will also decrease by about $20 \%$ due to the larger role played by both renewable energy and WtE facilities. Overall, the adoption of both carbon credit price and FIT are indicated as effective means to accelerate the transition of energy structure for reducing GHG emissions. Other considerations, such as public support, should also be accounted for decision makers to decide to implement interventions with encouragement or penalisation.

\section{Conclusion}

An investigative systematic modelling approach of studying FEW2 nexus in the Hunter Region, under the

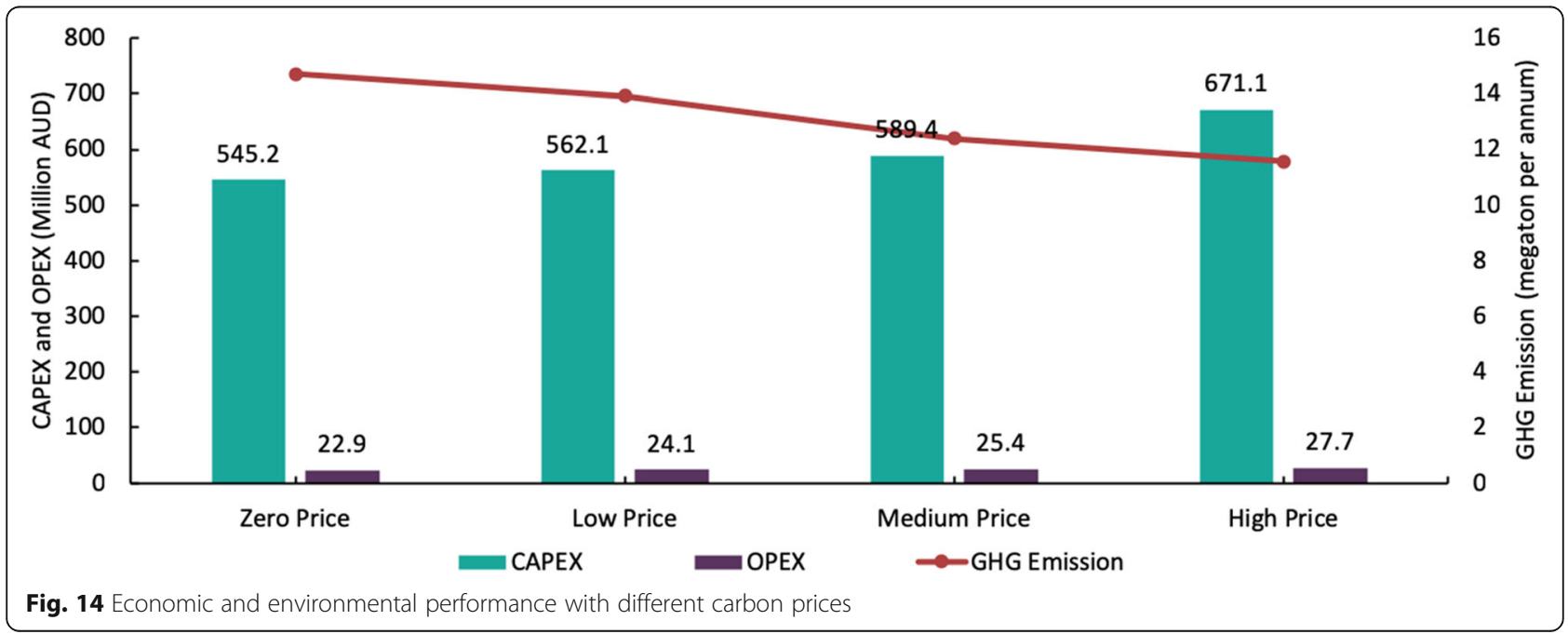




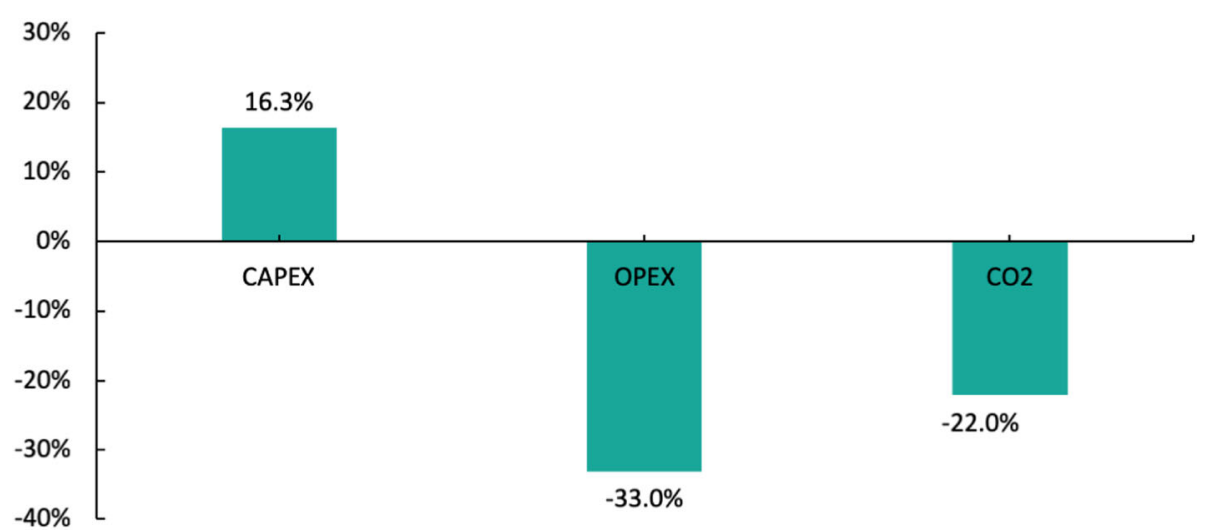

Fig. 15 Change in the three key indicators after applying FIT

assumptions presented, leads to the initial findings presented above. As a summary, the holistic approach supported by resilience.io proved to be insightful in decision-making process for water, energy and waste sectors in the context of FEW2. The feasibility of agentbased modelling and MILP optimisation model has also been further demonstrated, as the demand and resource flow supply are successfully simulated for the combined benefits of economy and environment in the context of Hunter Region. Overall, the effectiveness of resilience.io platform in developed country is demonstrated. Together with prior case studies of Ghana, the system modelling framework presents its robustness in various contexts of application.

Water reclamation technology, NEWater, is considered as the best candidate to mitigate extremely drought periods across the Hunter. About 35\% of wastewater need to be recycled for raw water production in order to avoid the water storage level from falling below level 1 restriction. To accommodate the decommission of Liddell and Bayswater power plant, solar panels, CCGTCCS and onshore wind energy conversion are most recommended due to relatively low costs or emissions. Through WtE pathway, a total of 854 GWh per annum renewable energy can be generated in 2036 and $94 \%$ of the generation from waste is in the form of biogas or syngas. By upgrading and injecting into gas grid, the gasto-electricity conversion loss can be avoided, and less energy transmission loss will incur. Biogas generation is thus considered to render more economic benefits than electricity. Two commonly adopted policy interventions-carbon credit price and feed-in tariff-are investigated to demonstrate their economic and environmental effect. Both policies will encourage the installation of WtE technologies when applied, which also leads to reduction in GHG emissions due to reduction in coal-fired electricity generation.
As the government of NSW has been elaborating the Hunter Regional Plan 2036 to further deliver prosperity for the region in a long term, the system approach has shown great benefits for decision makers through our local dissemination events [69]. Modelling work at this stage was still investigative. The model was used to establish and demonstrate the merits of a digitally driven systems approach and was not designed to support planning decision or investment case. As a next step, a Hunter stakeholder-oriented system model development-in particular on model validation and database development with wider coverage of promising technology options-will enable more robust modelling outputs to be generated. These outputs allow better informed investment and policy decisions, taking into account a wider range of opportunities, for which this paper is only a starting point. For example, the population model can be used to track existing skills and align education with future skill needs, something that we know is critical to the regional strategy and could be linked to the creation of local jobs and an attractive economic environment when evaluating different technical and policy options. Moreover, there is an opportunity to bring health metrics into the resilience.io platform, which could be used to build the economic case to invest in improving air quality in the Upper Hunter. The systems approach can then be seen as a starting point for the exploration of different visions and futures, with local stakeholders at the centre of the decision-making process. The data as well as simulated scenarios, will enable well-informed decisions and further detailed examination of options deemed attractive at the systems level. Following a systems approach, the interdependencies between infrastructure systems and sectors will continue to be at the core of planning integrated solutions at the national, regional and local level. 


\section{Nomenclature}

Indices and Sets.

$m$ metrics as CAPEX, OPEX, CO2.

tm major time period as years

j type of technology

$i, i^{\prime}$ (alias) zone/cell/district/region

$t$ minor time period as fraction of a single day

$r$ type of resources (material or energy)

\section{Continuous Variables}

$P(j, i, t, t m)$ production rate of technologies

$Q\left(r, i, i^{\prime}, t, t m\right)$ flow of $r$ from $i$ to $i^{\prime}$

$\operatorname{IM}(r, i, t, t m)$ import/export of resource

$R S(r, i, t, t m)$ net surplus of $r$ in $i$ in time period $t$ of $t m$

Integer Variables

INV $(j, i, t m)$ number of units of $j$ invested in time tm

$N(j, i, t m)$ number of tech $j$ in district $i$ in $\mathrm{tm}$

\section{Binary Variables}

$Y Q\left(r, i, i^{\prime}, t, t m\right)$ if the transportation of $r$ from $i$ to $i$ has been

built or not

$\operatorname{YIM}(r, i, t, t m)$ if the import/export of $r$ in district $i$ is allowed or not

\section{Other Parameters}

$Z$ the objective function

ObjWt objective function weights

$V M(m, t m)$ total value of $m$ in major time period $t m$

$V I J(j, m)$ technology investment coeffient in $m$

$V P J(j, m)$ technology process coeffient in $m$

$V Q(r, m)$ transportation coeffient per $\mathrm{km}$ of $\mathrm{r} / \mathrm{m}$

$V I(r, m)$ import value of $r / m$

PHI hours assinged for a year

$Q_{\max }$ max flow of resources

$I M_{\text {max }}$ max import/export flow of resources

$M U(j, r)$ rate of $r$ production per unit production of $j$

$X(i) X$ coordinate of $i$, in $\mathrm{km}$

$Y(i) Y$ coordinate of $i$, in $\mathrm{km}$

Math Formulas

$\operatorname{dist}\left(i, i^{\prime}\right) \sqrt{\left(X_{i}-X_{i}^{\prime}\right)^{2}+\left(Y_{i}-Y_{i}^{\prime}\right)^{2}}$

abs $(x)$ absolute value of $x$

\section{Supplementary information}

Supplementary information accompanies this paper at https://doi.org/10. 1186/s42480-020-0027-3.

Additional file 1. Part A: Modelling assumptions and data source; Part B: Modelling basis of water and wastewater technologies; Part C: Modelling basis of energy technologies; Part D: Modelling basis of WtE technologies; Part E: Modelling basis of Existing Facilities; Part F: Model size indicators. Part G: Present value analysis assumptions.

\section{Abbreviations}

ABM: Agent-based model; AD co: Anaerobic Digestion with municipal waste and liquid waste as co-feedstock; AD with THP: Anaerobic Digestion with Thermal Hydrolysis Pre-processing; AD: Anaerobic Digestion; AUD: Australian Dollar; BAU: Business as usual; CAPEX: Capital Expenditure; CCGTCCS: Combined cycle gas turbine with carbon capture and storage: EWF: Energy-Water-Food Nexus; FEW2: Food-Energy-Water-Waste Nexus;
FIT: Feed-in tariff; FTE: Full Time Equivalent; GAMA: Greater Accra Metropolitan Area; GHD: GHD Group Pty Ltd.; GHG: Greenhouse Gas; GLPK: GUN Linear Programming Kit; HW: Hunter Water; MILP: Mixed-Integer Linear Programming; MSW: Municipal solid waste; NSW: New South Wales; OPEX: Operating Expenditure; plasma: Plasma Gasification; PSA: Pressure Swing Adsorption; PUB: Public Utilities Board; PV: Present value;

RTN: Resource technology network; tpa: tonnes per annum; UES: Urban Energy System; UWOT: Urban Water Optioneering Tool; WtE: Waste to Energy; wtp: Waste Treatment Plant; wwtw: Wastewater Treatment Work

\section{Acknowledgements}

The authors are grateful to the industry and academia organisational collaborators of this project, including the Resilience Brokers and the Hunter Water Corporation of Australia. Special thanks to the Hunter Water for providing the valuable data and enabling this topic to be discussed. We also particularly thank David Derkenne who worked closely with the project team throughout the systems modelling of this study.

\section{Authors' contributions}

B. Feng implemented the mathematical models, generated the computational results, and prepared the paper. K. H van Dam, X. Wang and M. Guo developed the tools, and designed the analysis. S. Passmore designed the project and collected the data. N. Shah, and X. Wang supervised the work. All authors have contributed to the paper writing and given the approval to the final version of the manuscript.

\section{Funding}

Not applicable.

\section{Availability of data and materials}

All data generated or analysed during this study are included in this article or the supporting information attached with this article, except for part of Hunter Water Corporation data which are private and confidential.

\section{Competing interests}

The authors declare that they have no competing interests.

\section{Author details}

${ }^{1}$ Department of Chemical and Biomolecular Engineering, National University of Singapore, Singapore 117585, Singapore. ${ }^{2}$ Department of Chemical Engineering, Imperial College London, South Kensington Campus, London SW7 2AZ, UK. ${ }^{3}$ Resilience Brokers Ltd, London, 244-254 Cambridge Heath Road, London E2 9DA, UK.

Received: 9 October 2019 Accepted: 5 January 2020

Published online: 19 February 2020

References

1. Wang $X$, et al. A Nexus approach for sustainable urban energy-Water-waste systems Planning and operation. Environ Sci Technol. 2018;52(5):3257-66.

2. Bazilian $\mathrm{M}$, et al. Considering the energy, water and food nexus: towards an integrated modelling approach. Energy Policy. 2011;39(12):7896-906.

3. Muga HE, Mihelcic JR. Sustainability of wastewater treatment technologies. J Environ Manag. 2008;88(3):437-47.

4. FAO. The water-energy-food nexus: a new approach in support of food security and sustainable agriculture. 2014 [cited 2018 01.11]; Available from: http://www.fao.org/3/a-bl496e.pdf.

5. Garcia DJ, You F. The water-energy-food nexus and process systems engineering: a new focus. Comput Chem Eng. 2016;91:49-67.

6. The Atlantic. The deadstock dilemma: our toxic meat waste. 2010 [cited 2019 Jan 12]; Available from: https://www.theatlantic.com/health/archive/2 010/08/the-deadstock-dilemma-our-toxic-meat-waste/61191/.

7. Main, D. Two numbers: animal manure a growing headache in America. 2015 [cited 2019 Jan 12]; Available from: https://www.newsweek.com/2015/12/18/ two-numbers-animal-manure-growing-headache-america-402205.html.

8. American Chemistry Society. Sewage -- yes, poop -- could be a source of valuable metals and critical elements. [cited 2019 Jan 12]; Available from: https://www.eurekalert.org/pub_releases/2015-03/acs-s-y022015.php.

9. Mateo-Sagasta, J., L. Raschid-Sally, and A. Thebo, Global wastewater and sludge production, treatment and use, in Wastewater. 2015, Springer. p. 15-38. 
10. Bank T.W. What a waste: a global review of solid waste management. 2016 [cited 2019 Jan 12]; Available from: http://web.worldbank.org/WBSITE/ EXTERNAL/TOPICS/EXTURBANDEVELOPMENT/0, contentMDK:23172887pagePK:210058-piPK:210062-theSitePK:337178,00.html.

11. Henze $M$, et al. Wastewater treatment: biological and chemical processes: Springer Science \& Business Media; 2001.

12. Ghisellini P, Cialani C, Ulgiati S. A review on circular economy: the expected transition to a balanced interplay of environmental and economic systems. J Clean Prod. 2016;114:11-32

13. Lehmann S. In: Droege P, editor. 2.10 - conceptualizing the urban nexus framework for a circular economy: linking energy, water, food, and waste (EWFW) in Southeast-Asian cities, in urban energy transition (second edition): Elsevier; 2018. p. 371-98.

14. World Energy Council. World energy scenarios: composing energy futures to 2050. 2013 [cited 2019 Jan 12]; Available from: https://www.worldenergy. org/wp-content/uploads/2013/09/World-Energy-Scenarios_Composingenergy-futures-to-2050_Full-report.pdf.

15. Pan S-Y, et al. Strategies on implementation of waste-to-energy (WTE) supply chain for circular economy system: a review. J Clean Prod. 2015;108:409-21.

16. Endo $A$, et al. A review of the current state of research on the water, energy, and food nexus. J Hydrol Regional Stud. 2017;11:20-30.

17. Martinez-Hernandez E, Leach M, Yang A. Understanding water-energy-food and ecosystem interactions using the nexus simulation tool NexSym. Appl Energy. 2017;206:1009-21.

18. Endo A, et al. Methods of the water-energy-food Nexus. Water. 2015;7(10):5806.

19. Rozos E, Makropoulos C. Source to tap urban water cycle modelling. Environ Model Softw. 2013;41:139-50.

20. Behzadian, K., et al., Quantitative UWS performance model: WaterMet2. 2014.

21. Keirstead J, Jennings $M$, Sivakumar A. A review of urban energy system models: Approaches, challenges and opportunities. 2012;16:3847-66.

22. Dubreuil $\mathrm{A}$, et al. Water modeling in an energy optimization framework the water-scarce middle east context. Appl Energy. 2013;101:268-79.

23. Sufian M, Bala B. Modeling of urban solid waste management system: the case of Dhaka city. Waste Manag. 2007;27(7):858-68.

24. Fang D, Chen B. Linkage analysis for the water-energy nexus of city. Appl Energy. 2017;189:770-9.

25. Kan G, et al. Improving water quantity simulation \& forecasting to solve the energy-water-food nexus issue by using heterogeneous computing accelerated global optimization method. Appl Energy. 2018;210:420-33.

26. Garcia D, You F. Systems engineering opportunities for agricultural and organic waste management in the food-water-energy nexus. Curr Opin Chem Eng. 2017;18:23-31.

27. Kibler KM, et al. Food waste and the food-energy-water nexus: a review of food waste management alternatives. Waste Manag. 2018;74:52-62.

28. Hering JG, et al. A changing framework for urban Water systems. Environ Sci Technol. 2013;47(19):10721-6.

29. Triantafyllidis $C P$, et al. An integrated optimisation platform for sustainable resource and infrastructure planning. Environ Model Softw. 2018;101:146-68

30. Bieber $\mathrm{N}$, et al. Sustainable planning of the energy-water-food nexus using decision making tools. Energy Policy. 2018;113:584-607.

31. Wang $X$, et al. Water and energy Systems in Sustainable City Development: a case of sub-saharan Africa. Proc Eng. 2017;198:948-57.

32. Wang $X$, et al. Waste-Energy-Water systems in sustainable city development using the resilience. io platform, in Computer Aided Chemical Engineering: Elsevier; 2017. p. 2377-82.

33. Bell M, Pavitt K. Technological accumulation and industrial growth: contrasts between developed and developing countries. Technol Global Econ Perform. 1997:83137:83-137.

34. World Nuclear Association. Australia's uranium and nuclear power prospects. 2018 [cited 2018 Jan 12]; Available from: http://world-nuclear. org/information-library/country-profiles/countries-a-f/australia.aspx.

35. Australian Social Science Archive. Opinion Poll D0237: Australian Gallup Poll July 1975. 1975 [cited 2019 Jan 12]; Available from: http://assda.anu.edu.au/ polls/D0237.html.

36. Wei T, et al. Developed and developing world responsibilities for historical climate change and CO2 mitigation. Proc Natl Acad Sci U S A. 2012;109(32): 12911-5.

37. Development, C.f.G. Developing countries are responsible for 63 percent of current carbon emissions. 2015 [cited 2019 Jan 12]; Available from: https:// www.cgdev.org/media/developing-countries-are-responsible-63-percentcurrent-carbon-emissions
38. Environment, N.P. Goal 1 - The leading regional economy in Australia. 2018 [cited 2019 Jan 12]; Available from: https://www.planning.nsw.gov.au/Plansfor-your-area/Regional-Plans/Hunter/Hunter-regional-plan/The-leadingregional-economy-in-Australia.

39. Hunter Water. Water supply. 2016; Available from: https://www.hunterwater. com.au/Water-and-Sewer/Water-Supply/Water-Supply.aspx.

40. NSW Department of Industry. Greater hunter regional water strategy. 2018 [cited 2019 Jan 12]; Available from: https://www.industry.nsw.gov.au/_ data/assets/pdf_file/0008/196055/greater-hunter-regional-water-strategy.pdf.

41. NSW Goverment Planning \& Environment. The hunter regional plan 2036. 2016 [cited 2019 Jan 12]; Available from: https://www.planning. nsw.gov.au/ /media/Files/DPE/Plans-and-policies/hunter-regionalplan-2036-2016-10-18.ashx.

42. State of NSW and Environment Protection Authority. NSW waste avoidance and resource recovery strategy 2014-21. 2014 [cited 2019 Jan 12]; Available from: https://www.epa.nsw.gov.au/ /media/EPA/Corporate\%20Site/ resources/wastestrategy/140876-WARR-strategy-14-21.ashx.

43. Mata-Alvarez J, Macé S, Llabrés P. Anaerobic digestion of organic solid wastes. An overview of research achievements and perspectives. Bioresour Technol. 2000;74(1):3-16.

44. Appels $L$, et al. Principles and potential of the anaerobic digestion of wasteactivated sludge. Prog Energy Combust Sci. 2008;34(6):755-81.

45. Higman C. In: Miller BG, Tillman DA, editors. Chapter 11 - gasification, in combustion engineering issues for solid fuel systems. Burlington: Academic Press; 2008. p. 423-68.

46. Zhang Q, et al. Gasification of municipal solid waste in the plasma gasification melting process. Appl Energy. 2012;90(1):106-12.

47. Pinto $F$, et al. Effect of experimental conditions on co-gasification of coal, biomass and plastics wastes with air/steam mixtures in a fluidized bed system. Fuel. 2003;82(15-17):1967-76.

48. Gao J, et al. A thermodynamic analysis of methanation reactions of carbon oxides for the production of synthetic natural gas. RSC Adv. 2012;2(6):2358-68.

49. Alonso-Vicario A, et al. Purification and upgrading of biogas by pressure swing adsorption on synthetic and natural zeolites. Microporous Mesoporous Mater. 2010;134(1-3):100-7.

50. Dong $F$, et al. The Petlyuk PSA process for the separation of ternary gas mixtures: exemplification by separating a mixture of CO2-CH4-N2. Sep Purif Technol. 1999:16(2):159-66.

51. Resilience Brokers. resilience.io. 2016 [cited 2019 Jan 12]; Available from: https://resiliencebrokers.org/resilience-io-2/.

52. van Dam KH, et al. Model-based decision-support for waste-to-energy pathways in New South Wales, Australia, in computer aided chemical engineering: Elsevier; 2019. p. 1765-70.

53. Ausgrid. Ausgrid average electricity consumption by LGA 2016. 2016 [cited 2019 Jan 12]; Available from: https://www.ausgrid.com.au/-/media/ Documents/Data-to-share/Average-electricity-use/Ausgrid-averageelectricity-consumption-by-LGA-201516.pdf.

54. AEMO. Australian energy market operator. 2018 [cited 2019 Jan 12]; Available from: https://www.aemo.com.au/.

55. GHD Pty Ltd, Hunter water corporation hunter water-planning technical advice adhoc thermal hydrolysis options comparison, in HWC-Planning Technical Advice Adhoc, 2218668. 2018.

56. Hunter Water Corporation, Biosolids costs summary. 2018.

57. Talent with Energy. Renewable Gases Supply Infrastructure. 2013 [cited 2019 Jan 12]; Available from: https://www.cityofsydney.nsw.gov.au/_data/assets/ pdf_file/0005/153284/Technical-Appendix-2-Renewable-Gases-SupplyInfrastructure-Talent-With-Energy.pdf.

58. MRA Consulting Group, Market analysis of organic waste feedstocks in the lower hunter region. 2018.

59. NSW Goverment. Hunter climate change snapshot. 2018 [cited 2018 Jan 12]; Available from: http://www.climatechange.environment.nsw.gov.au/ / media/NARCLim/Files/Regional\%20Downloads/Climate\%20Change\%2 OSnapshots/Huntersnapshot.pdf.

60. Hunter Water. Water storage levels. 2019 [cited 2019 Jan 12]; Available from: https://www.hunterwater.com.au/Water-and-Sewer/Water-Supply/WaterStorage-Levels.aspx

61. Hunter Water. Water restrictions. 2018 [cited 2019 Jan 12]; Available from: https://www.hunterwater.com.au/Your-Account/Water-Usage/WaterRestrictions.aspx

62. Public Utilities Board. NEWater. 2018 [cited 2019 Jan 12]; Available from: https://www.pub.gov.sg/watersupply/fournationaltaps/newater. 
63. Deloitte Access Economics. Prospects and challenges for the Hunter region: A strategic economic study. 2012 [cited 2019 Jan 12]; Available from: https://www.pc.gov.au/_data/assets/pdf_file/0006/125754/sub010-labourmobility.pdf.

64. The United Nations. Sustainable development goal 7. 2018 [cited 2019 Jan 12]; Available from: https://sustainabledevelopment.un.org/sdg7.

65. Office of Environment and Heritage. Fact sheet: achieving net-zero emissions by 2050. 2016 [cited 2019 Jan 12]; Available from: https:/www. environment.nsw.gov.au/-/media/OEH/Corporate-Site/Documents/Climatechange/achieving-net-zero-emissions-by-2050-fact-sheet-160604.pdf.

66. Centre for Public Impact. The carbon tax in Australia. 2017 [cited 2019 Jan 12]; Available from: https://www.centreforpublicimpact.org/case-study/ carbon-tax-australia/.

67. The World Bank. What is carbon pricing? 2017 [cited 2019 Jan 12]; Available from: https://carbonpricingdashboard.worldbank.org/what-carbon-pricing.

68. Parliament of Australia. Feed-in tariffs. 2011 [cited 2019 Jan 12]; Available from: https://www.aph.gov.au/About_Parliament/Parliamentary_ Departments/Parliamentary_Library/Browse_by_Topic/ClimateChangeold/ governance/domestic/national/feed

69. Resilience Brokers A collaborative systems approach to a sustainable hunter. 2019. [cited 2019 Jan 12]; Available from: https://resiliencebrokers.org/ working-with-cities/\#projects.

\section{Publisher's Note}

Springer Nature remains neutral with regard to jurisdictional claims in published maps and institutional affiliations.

Ready to submit your research? Choose BMC and benefit from:

- fast, convenient online submission

- thorough peer review by experienced researchers in your field

- rapid publication on acceptance

- support for research data, including large and complex data types

- gold Open Access which fosters wider collaboration and increased citations

- maximum visibility for your research: over $100 \mathrm{M}$ website views per year

At BMC, research is always in progress.

Learn more biomedcentral.com/submissions 